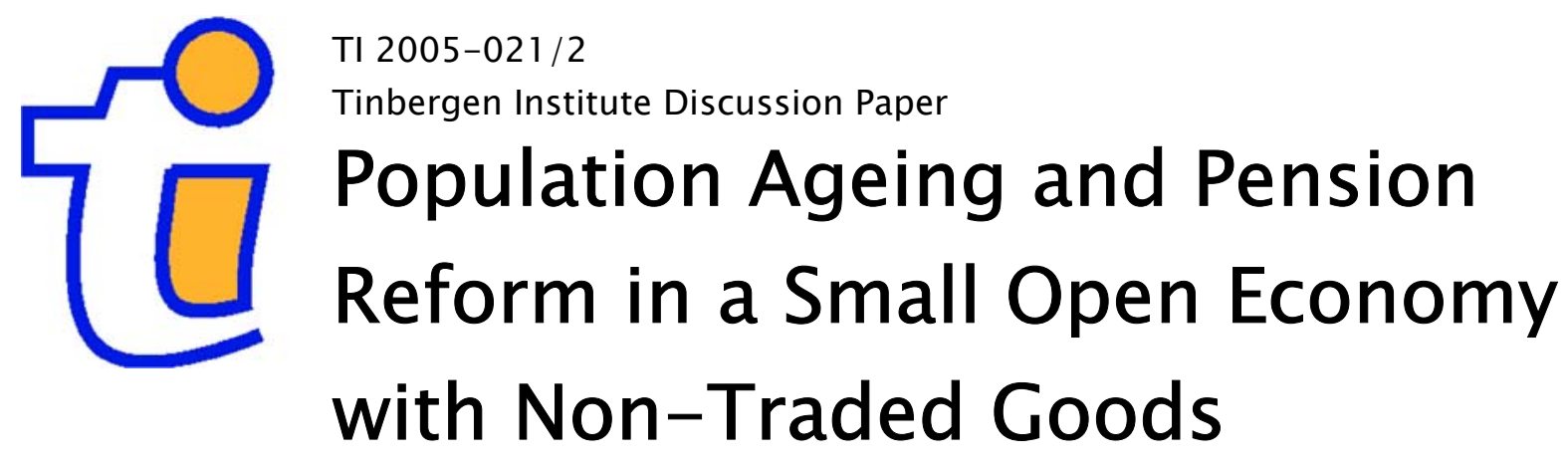

Leon Bettendorf

Ben Heijdra²

'Department of Economics, Erasmus University, and Tinbergen Institute,

2 Department of Economics, University of Groningen. 


\section{Tinbergen Institute}

The Tinbergen Institute is the institute for economic research of the Erasmus Universiteit Rotterdam, Universiteit van Amsterdam, and Vrije Universiteit Amsterdam.

Tinbergen Institute Amsterdam

Roetersstraat 31

1018 WB Amsterdam

The Netherlands

Tel.: $\quad+31(0) 205513500$

Fax: $\quad+31(0) 205513555$

Tinbergen Institute Rotterdam

Burg. Oudlaan 50

3062 PA Rotterdam

The Netherlands

Tel.: $\quad+31(0) 104088900$

Fax: $\quad+31(0) 104089031$

Please send questions and/or remarks of nonscientific nature to driessen@tinbergen.nl.

Most TI discussion papers can be downloaded at http://www.tinbergen.nl. 


\title{
Population Ageing and Pension Reform in a Small Open Economy with Non-Traded Goods
}

\author{
Leon J.H. Bettendorf* \\ Erasmus University
}

\author{
Ben J. Heijdra ${ }^{\sharp}$ \\ University of Groningen
}

April 2004

\begin{abstract}
In this paper we study the implications of population ageing in an economy with a sizeable non-traded goods sector. To this effect a highly stylized micro-founded macro model is constructed in which the age structure of the population plays a non-trivial role. The model distinguishes separate birth and death probabilities (thus allowing for net population change), allows for age-dependent labour productivity (thus mimicing life-cycle saving), and includes a rudimentary pension system (thus allowing for intergenerational redistribution). The model is used to analytically study demographic and pension shocks. JEL codes: D91, E13, F41, H55. Keywords: fertility rate, overlapping generations, pension reform, demographic shocks, non-traded goods.
\end{abstract}

\section{Introduction}

The western world is ageing rapidly. As was recently argued by Lee (2003), the ageing process since the postwar period can be attributed both to increased longevity and reduced fertility. As a result, the population share of elderly people has increased dramatically. For example, for the countries comprising the Most Developed Regions, the old-age dependency ratio ${ }^{1}$ was $12 \%$ in $1950,21 \%$ in 2000 , and is projected to increase to $44 \%$ in 2050 - see United Nations (2003). Between the Most Developed Regions countries there is quite a lot of variation. For example, Japan had an old-age dependency ratio in 2000 of only $25 \%$ but this ratio is expected to rise to $72 \%$ by 2050 . For a number of small open European economies the corresponding figures are: Belgium (from $26 \%$ to $47 \%$ ), Germany (from $24 \%$ to $49 \%$ ), Italy (from $27 \%$ to

\footnotetext{
*Erasmus University, P.O. Box 1738, 3000 DR Rotterdam, The Netherlands. Phone: +31-10-408-1808, E-mail: bettendorf@few.eur.nl.

${ }^{\sharp}$ Department of Economics, University of Groningen, P.O. Box 800, 9700 AV Groningen, The Netherlands. Phone: +31-50-363-7303, Fax: +31-50-363-7337, E-mail: b.j.heijdra@eco.rug.nl.

${ }^{1}$ The old-age dependency ratio is defined as the ratio of the elderly population (65+ years) to the workingage (15-64 years) population.
} 
$65 \%$ ), and the Netherlands (from $20 \%$ to $42 \%$ ). The figures for the United States are less drastic but still noticeable (from $19 \%$ in 2000 to $32 \%$ in 2050 ).

It is widely believed that demographic changes of such order of magnitude will have profound and long-lasting economic effects, both on the world as a whole and on individual countries. This paper focuses on the second issue by posing the question: How will small open economies be affected by ageing? We answer this question in two steps. First, we analyze the macroeconomic effects of various (pure and composite) demographic shocks in a model of a small open economy with a non-traded goods sector. We show how changes in the demography influence capital accumulation, household consumption, aggregate output, and economic growth, both at impact, during transition, and in the long run.

In the second step, we study the macroeconomic and welfare effects of pension reform. Many western countries rely heavily on unfunded pay-as-you-go (PAYG) pension systems which may become untenable due to the ageing process. Of course, in the absence of Ricardian equivalence, PAYG systems are equivalent to government debt and their reform will therefore exert significant intergenerational effects. Simply put, both explicit and implicit public debt represent an intergenerational burden in such a setting.

In contrast with the vast majority of studies on population ageing, we employ an analytical framework which is simple and flexible enough to establish our results. ${ }^{2}$ The advantage of doing so is that we are thus able to highlight the key economic mechanisms by which ageing and pension reform exert their influence on the economy. ${ }^{3}$ Our analysis makes use of modelling insights from two main bodies of literature. First, in order to allow for overlapping generations (OG) and the possibility of Ricardian non-equivalence, we employ the framework originally developed by Yaari (1965) and Blanchard (1985), and further extended by Buiter (1988), Giovannini (1988), Weil (1989), and Bovenberg (1993). In this framework, potentially disconnected generations are born at each instant and all agents face a constant probability of death. By distinguishing birth and death rates, the model is suitable to study demographic shocks both with and without Ricardian equivalence. We enrich the OG framework by allowing for age-dependent productivity (to capture the notion of "saving for a rainy day") and by including a simple PAYG pension system. ${ }^{4}$

The second key building block of our analysis concerns the body of assumptions regarding international trade in goods and the mobility of physical and financial assets. In accordance with the literature we abstract from capital market constraints and assume that financial assets are perfectly mobile internationally. This means that the world interest rate, measured in terms of the traded good, is constant. Since small open economies often have a

\footnotetext{
${ }^{2}$ Most studies on population ageing employ dynamic calibrated computable general equilibrium (CGE) models in the style of Auerbach and Kotlikoff (1987). See, for example, Hubbard and Judd (1987), Auerbach et al. (1989), Cutler et al. (1990), Auerbach, Cai and Kotlikoff (1991), and Broer (2001).

${ }^{3}$ Like Gertler (1999) we do not consider our approach to be a substitute for large-scale numerical simulation models, but rather to be supplementary to such models.

${ }^{4}$ This pension system is similar to the one suggested by Nielsen (1994).
} 
sizeable non-traded sector, we follow Turnovsky $(1997$, ch. 4) by distinguishing two separate production sectors. The traded (or non-sheltered) sector produces an internationally traded good whose price is set in world markets. In contrast, the non-traded sector produces only for home absorption, and as a result the real exchange rate is determined endogenously within the model. We abstract from international physical capital mobility by assuming that only non-traded goods are used for investment purposes. This approach implies economywide adjustment costs of investment due to the increasing marginal cost of production in the non-traded sector. ${ }^{5}$

The remainder of the paper is organized as follows. In Section 2 we present the model and demonstrate its main properties. The model is saddle-point stable, but the relative capital intensity of the two sectors determines qualitatively the form of the transitional dynamics in the real exchange rate. Indeed, in the empirically relevant core case, in which the nontraded sector is relatively labour intensive, there is no transitional dynamics in the real exchange rate at all! In the remainder of the paper we restrict attention on this core case. In Section 3, we discuss the macroeconomic effects of composite demographic shocks. In the first of such shocks, there is a proportionate fall in the fertility and death rates so as to yield a stationary population growth rate. Under this scenario, there is an investment boom during the early phases of adjustment but capital crowding out (due to increased consumption of non-tradeables) in the long run. The second scenario consists of a drop in the fertility rate accompanied by an increase in the death rates so as to keep the rate of generational turnover constant but to reduce the population growth rate. Per capita consumption and financial assets both rise monotonically, but the impact and long-run effects on investment are ambiguous and depend critically on the severity of the adjustment costs (i.e. on the share of non-traded goods consumption).

In the remainder of Section 3 we study two types of pension reform, namely a decrease in the pension benefit and an increase in the retirement age (both accompanied by a reduction in the pension premium to balance the budget of the PAYG system). For the relevant case, with the interest rate exceeding the rate of population growth (the so-called Aaron condition), the reform leads to long-run increases in consumption and financial assets but a decrease in the capital stock. Again, this long-run crowding out of capital occurs because consumption of non-traded goods increases.

In Section 4 we study the intergenerational welfare effects for the two types of pension reform. We assume that the Aaron condition holds. For the pension reduction we obtain the usual result that the oldest of those generations alive at the time of the shock loose out as a result of it. ${ }^{6}$ An increase in the pension age leaves pensioners unaffected and makes future generations strictly better off. The oldest of the working-age generations bear the brunt of the

\footnotetext{
${ }^{5}$ See also van Wincoop (1993), Brock and Turnovky (1994), Turnovsky (1997, p. 104), and Hsieh, Chang, and Lai (1998).

${ }^{6}$ This result is familiar from the standard two-generation Diamond (1965) model.
} 
reform. We close this section by developing simple conditions (involving structural economic and demographic parameters) under which majoritarian pension reform is feasible.

Finally, in Section 5 we present some concluding thoughts and give some suggestions for future research.

\section{The model}

\subsection{Households}

\subsubsection{Individual households}

The utility functional in period $t$ of the representative agent born at time $v$ is denoted by $\Lambda(v, t)$ and takes the following form: ${ }^{7}$

$$
\Lambda(v, t) \equiv \int_{t}^{\infty}\left[\frac{\bar{c}(v, \tau)^{1-1 / \sigma_{U}}-1}{1-1 / \sigma_{U}}\right] e^{(\rho+\beta)(t-\tau)} d \tau,
$$

where $\bar{c}$ is a composite consumption good (see below), $\sigma_{U}$ is the intertemporal substitution elasticity $\left(\sigma_{U} \geq 0\right), \rho$ is the pure rate of time preference $(\rho>0)$, and $\beta$ is the instantaneous probability of death $(\beta \geq 0)$. Following Armington (1969) we assume that composite consumption is a constant-elasticity-of-substitution (CES) aggregate of traded and non-traded goods $\left(\bar{c}^{T}\right.$ and $\bar{c}^{N}$, respectively):

$$
\bar{c}(v, \tau) \equiv\left[\varepsilon_{C} \bar{c}^{T}(v, \tau)^{\left(\sigma_{C}-1\right) / \sigma_{C}}+\left(1-\varepsilon_{C}\right) \bar{c}^{N}(v, \tau)^{\left(\sigma_{C}-1\right) / \sigma_{C}}\right]^{\sigma_{C} /\left(\sigma_{C}-1\right)},
$$

where $\sigma_{C}$ is the so-called Armington elasticity of substitution between the two types of goods. It is assumed that $0 \leq \sigma_{C} \ll \infty$, i.e. the goods are imperfect substitutes in consumption.

The household budget identity, expressed in terms of the traded good, is given by:

$$
\dot{\bar{a}}(v, \tau)=\left(r^{F}+\beta\right) \bar{a}(v, \tau)+\left(\frac{W I^{N}(v, \tau)}{P^{T}(\tau)}\right)-\bar{c}^{T}(v, \tau)-\left(\frac{P^{N}(\tau)}{P^{T}(\tau)}\right) \bar{c}^{N}(v, \tau),
$$

where $r^{F}$ is the exogenously given (constant) world rate of interest, $W I^{N}(v, \tau)$ is agedependent non-interest income net of lump-sum taxes/transfers (see below), $P^{T}$ and $P^{N}$ denote, respectively, the price of traded and non-traded goods, and $\bar{a}(v, \tau)$ is real financial wealth of the household. The return $\beta \bar{a}$ is the actuarially fair annuity paid by the competitive life insurance company - see Yaari (1965) and Blanchard (1985). A dot above a variable denotes that variable's time rate of change, e.g. $\dot{\bar{a}}(v, \tau) \equiv d \bar{a}(v, \tau) / d \tau$.

Financial wealth can be held in the form of capital goods $(\bar{k})$, domestic government bonds $\left(\bar{a}^{G}\right)$, or foreign bonds $\left(\bar{a}^{F}\right)$. The first two assets are denominated in terms of non-traded

\footnotetext{
${ }^{7}$ Variables with a bar overstrike apply to individual households. All derivations are documented in a separate Mathematical Appendix (see Bettendorf and Heijdra, 2004). Some key results are derived in the Appendix to the paper.
} 
goods so real financial wealth is:

$$
\bar{a}(v, \tau) \equiv\left(\frac{P^{N}(\tau)}{P^{T}(\tau)}\right)\left[\bar{k}(v, \tau)+\bar{a}^{G}(v, \tau)\right]+\bar{a}^{F}(v, \tau)
$$

Following Nielsen (1994), we assume that the government maintains the following PAYG pension scheme. Young households, with ages ranging from zero (newborns) to $\pi$ pay a lumpsum tax equal to $\bar{T}_{W}(\tau) \equiv \bar{t}_{W} P^{T}(\tau)$. In contrast, old households, with ages ranging from $\pi$ to infinity, receive a lump-sum transfer of $\bar{Z}_{R}(\tau) \equiv \bar{z}_{R} P^{T}(\tau)$. This scheme is run on a balanced-budget basis (see below). We shall refer to $\pi$ somewhat loosely as the retirement age. ${ }^{8}$ Under these assumptions, non-interest income takes the following form:

$$
\frac{W I^{N}(v, \tau)}{P^{T}(\tau)}=\left\{\begin{array}{ll}
\left(1-t_{L}\right) \frac{W^{N}(v, \tau)}{P^{T}(\tau)}-\bar{t}_{W} & \text { for } \tau-v \leq \pi \\
\left(1-t_{L}\right) \frac{W^{N}(v, \tau)}{P^{T}(\tau)}+\bar{z}_{R} & \text { for } \tau-v>\pi
\end{array},\right.
$$

where $t_{L}$ is a proportional labour income tax and $W^{N}(v, \tau)$ is the wage received at time $\tau$ by a worker born in period $v$. The age-dependency of the wage rate results from the fact that labour productivity is age-dependent.

The age-dependency of labour productivity is modelled as follows. The efficiency units of labour supplied by a household of generation $v$ at time $\tau$ is denoted by $\bar{n}(v, \tau)$ and can be written as follows:

$$
\bar{n}(v, \tau) \equiv E(\tau-v) \bar{l}(v, \tau),
$$

where $\bar{l}(v, \tau)=1$ is raw labour hours and $E(\tau-v)$ is the efficiency index. Following Blanchard (1985, pp. 235-238) we assume that the efficiency index falls exponentially with the age of the household:

$$
E(\tau-v)=\omega_{0} e^{-\alpha(\tau-v)},
$$

where $\omega_{0}$ is some positive constant and $\alpha(>0)$ regulates the speed at which efficiency falls with age. According to (2.7), a 20-year old worker is $e^{10 \alpha}$ times as productive as a 30-year old colleague.

In the planning period $t$, the household chooses paths for traded and non-traded goods consumption and for financial assets in order to maximize lifetime utility (2.1) subject to the flow budget identity (2.3) and a solvency condition, taking as given its initial level of financial assets $\bar{a}(v, t)$. We solve the household decision problem by means of two-stage budgeting.

\footnotetext{
${ }^{8}$ Note that households do not actually retire from the labour force-surviving households of all ages inelastically supply a single unit of raw labour throughout their lives (see also below). Gertler (1999) models exogenous but stochastic retirement as a two-stage Poisson process. In his model, agents face a random transition from work to retirement and subsequently from retirement to death.
} 
In the first stage we define full consumption, $\bar{x}$, as the sum of spending on traded and non-traded consumption goods:

$$
\bar{x}(v, \tau) \equiv \bar{c}^{T}(v, \tau)+\left(\frac{P^{N}(\tau)}{P^{T}(\tau)}\right) \bar{c}^{N}(v, \tau) .
$$

In the planning period the household allocates a proportion ${ }^{9}$ of its total wealth to full consumption:

$$
\begin{aligned}
\bar{x}(v, t) & =[\Delta(t)]^{-1}\left[\bar{a}(v, t)+\bar{a}^{H}(v, t)\right], \\
\Delta(t) & \equiv \int_{t}^{\infty}\left(\frac{P_{C}(\tau)}{P_{C}(t)}\right)^{1-\sigma_{U}} e^{\left[\left(1-\sigma_{U}\right)\left(r^{F}+\beta\right)+\sigma_{U}(\rho+\beta)\right](t-\tau)} d \tau,
\end{aligned}
$$

where $P_{C}$ is the true price index for composite consumption $\bar{c}^{10}$ and where $\bar{a}^{H}$ is human wealth:

$$
\bar{a}^{H}(v, t) \equiv \int_{t}^{\infty}\left(\frac{W I^{N}(v, \tau)}{P^{T}(\tau)}\right) e^{\left(r^{F}+\beta\right)(t-\tau)} d \tau .
$$

Human wealth represents the present discounted value of after-tax non-interest income (i.e. the value of the time endowment), using the annuity rate of interest for discounting. An alternative characterization of the household's optimal dynamic plans makes use of the Euler equation for full consumption which can be written as follows:

$$
\frac{\dot{\bar{x}}(v, t)}{\bar{x}(v, t)}-\frac{\dot{P}_{C}(t)}{P_{C}(t)}=\sigma_{U}\left(r^{F}-\frac{\dot{P}_{C}(t)}{P_{C}(t)}-\rho\right) .
$$

The left-hand side of this expression represents the optimal growth rate of composite consumption, $\dot{\bar{c}}(v, t) / \bar{c}(v, t)$. The slope of this time profile depends in the usual manner on the magnitude of the intertemporal substitution elasticity, $\sigma_{U}$, and on the gap between the "consumption rate of interest" and the rate of pure time preference. In the logarithmic case (with $\sigma_{U}=1$ ), the inflation rate in the true price index for composite consumption drops out of (2.12) and the time profile of full consumption is proportional to $r^{F}-\rho$.

In the second stage, consumption of traded and of non-traded goods are related to the level of full consumption. The key expressions are:

$$
\begin{aligned}
\bar{c}^{T}(v, t) & =\left[1-\omega_{N}(t)\right] \bar{x}(v, t), \\
\left(\frac{P^{N}(t)}{P^{T}(t)}\right) \bar{c}^{N}(v, t) & =\omega_{N}(t) \bar{x}(v, t),
\end{aligned}
$$

\footnotetext{
${ }^{9}$ Note that if we let $\sigma_{U} \rightarrow 1$ in (2.1), then $U$ is logarithmic and the full consumption propensity simplifies to $\Delta^{-1}=\rho+\beta$.

${ }^{10}$ This true price index is defined as follows:
}

$$
P_{C}(t) \equiv \begin{array}{lll}
\left(\varepsilon_{C}\right)^{\sigma_{C}}+\left(1-\varepsilon_{C}\right)^{\sigma_{C}} & {\frac{P}{P^{N}(t)}}^{1-\sigma_{C}}{ }^{1 /\left(1-\sigma_{C}\right)} & \text { for } \sigma_{C} \neq 1 \\
\frac{1}{\varepsilon_{C}}{ }^{\varepsilon_{C}} \frac{P^{N}(t)}{\left(1-\varepsilon_{C}\right) P^{T}(t)} & \text { for } \sigma_{C}=1
\end{array}
$$


where $\omega_{N}$ is a complicated function of the relative price of non-traded goods. ${ }^{11}$

\subsubsection{Demography}

In order to allow for non-zero population growth, we employ the analytical framework developed by Buiter (1988). This framework distinguishes the probability of death $\beta(\geq 0)$ and the birth rate $\eta(>0)$ and thus allows for net population growth or decline. We denote the population size at time $t$ by $L(t)$. In the absence of international migration, the growth rate of the population, $n_{L}$, is equal to the difference between the birth and death rates: ${ }^{12}$

$$
\frac{\dot{L}(t)}{L(t)}=\eta-\beta \equiv n_{L}
$$

By solving (2.15) subject to the initial condition $L(0)=1$, we find the path for the aggregate population:

$$
L(t)=e^{n_{L} t} .
$$

The size of a newborn generation is assumed to be proportional to the current population:

$$
L(v, v)=\eta L(v) .
$$

Since the death rate is constant and cohorts are assumed to be large, the size of each generation falls exponentially according to:

$$
L(v, t)=e^{\beta(v-t)} L(v, v), \quad t \geq v .
$$

By substituting (2.16) and (2.17) into (2.18) we finally obtain: ${ }^{13}$

$$
L(v, t)=\eta e^{\eta v} e^{-\beta t} .
$$

Given this demographic structure, $1-e^{-\eta \pi}$ represents the population fraction of young workers (whose age is less than $\pi$ ) and $e^{-\eta \pi}$ is the population fraction of old workers ("pensioners" whose age exceeds $\pi$ ). The old-age dependency ratio is thus given by $\operatorname{dep}(\pi) \equiv$ $e^{-\eta \pi} /\left[1-e^{-\eta \pi}\right]$, where $\varepsilon \equiv-d \ln d e p(\pi) / d \ln \pi=\eta \pi /\left(1-e^{-\eta \pi}\right)>1$ is the elasticity of this ratio with respect to the pension age.

\footnotetext{
${ }^{11}$ Note that $\omega_{N}$ is defined as follows:

$$
\omega_{N}(t) \equiv \frac{\left(1-\varepsilon_{C}\right)^{\sigma_{C}} P^{N}(t)^{1-\sigma_{C}}}{\left(\varepsilon_{C}\right)^{\sigma_{C}}\left[P^{T}(t)\right]^{1-\sigma_{C}}+\left(1-\varepsilon_{C}\right)^{\sigma_{C}}\left[P^{N}(t)\right]^{1-\sigma_{C}}} .
$$
}

The key thing to note in (2.13)-(2.14) is that our homothetic preference structure rules out age effects in $\omega_{N}(\cdot)$. Age-dependency cannot be incorporated as it would destroy the simple aggregation properties of the model.

${ }^{12}$ Below we shall allow $\beta$ and $\eta$ to be time-dependent. Age-dependency cannot be incorporated as it would destroy the simple aggregation properties of the model.

${ }^{13} \mathrm{An}$ attractive feature of the Buiter formulation is that it nests two influential OLG models as special cases. Indeed, by setting $\eta=\beta>0$ the Blanchard (1985) model is obtained and by setting $\eta>0$ and $\beta=0$ the Weil (1989) model is obtained. In addition, the Buiter model nests the representative-agent model of Cutler et al. (1990) if we set $\eta=0$ (no disconnected generations) and $\beta<0$ (positive intra-dynasty population growth). See also Bovenberg (1993, p. 8, fn.3) 


\subsubsection{Aggregate household sector}

Aggregate variables are calculated as the integral of the generation-specific values weighted by the corresponding generation sizes. For example, aggregate full consumption, $X(t)$, is defined as:

$$
X(t) \equiv \int_{-\infty}^{t} L(v, t) \bar{x}(v, t) d v,
$$

where $L(v, t)$ and $\bar{x}(v, t)$ are given in, respectively, (2.19) and (2.9). It follows that aggregate full consumption can be written as:

$$
X(t)=\Delta(t)^{-1}\left[A(t)+A^{H}(t)\right],
$$

where $A(t)$ is aggregate financial wealth and $A^{H}(t)$ is aggregate human wealth.

The aggregate Euler equation for full consumption is obtained by differentiating (2.20) with respect to time and noting (2.19):

$$
\dot{X}(t)=\int_{-\infty}^{t} L(v, t) \dot{\bar{x}}(v, t) d v+\eta L(t) \bar{x}(t, t)-\beta X(t) .
$$

By substituting (2.12) into (2.22) and dividing by $X(t)$ we obtain:

$$
\frac{\dot{X}(t)}{X(t)}=\left[\sigma_{U}\left[r^{F}-\rho\right]+\left(1-\sigma_{U}\right) \frac{\dot{P}_{C}(t)}{P_{C}(t)}\right]+\left[\frac{\eta L(t) \bar{x}(t, t)-\beta X(t)}{X(t)}\right] .
$$

The first term in square brackets on the right-hand side is the growth rate of individual full consumption $(\dot{\bar{x}}(v, t) / \bar{x}(v, t))$ whilst the second term is the generational turnover term which itself depends on the demographic parameters. Growth in aggregate full consumption is boosted because of the arrival of new agents (who start to consume out of human wealth) but it is slowed down by the death of a cross-section of the population.

In the Appendix we show that (2.23) can be simplified to:

$$
\frac{\dot{X}(t)}{X(t)}=\sigma_{U}\left[r^{F}-\rho\right]+\alpha+n_{L}+\left(1-\sigma_{U}\right) \frac{\dot{P}_{C}(t)}{P_{C}(t)}-\frac{\eta \gamma L(t)+(\alpha+\eta) A(t)}{\Delta(t) X(t)},
$$

where $\gamma$ is a complicated term involving the parameters of the pension system:

$$
\frac{\gamma}{r^{F}+\alpha+\beta} \equiv\left(\frac{e^{-\beta \pi}}{1-e^{-\eta \pi}}\right)\left(\frac{\bar{z}_{R}}{r^{F}+\beta}\right)\left(\frac{e^{-r^{F} \pi}-e^{-n_{L} \pi}}{n_{L}-r^{F}}\right)>0 .
$$

According to (2.24), aggregate full consumption growth differs from individual full consumption growth for two main reasons. First, aggregate growth exceeds individual growth if there is positive net population growth (i.e. if $n_{L}>0$ ) or if labour efficiency declines with age (i.e. if $\alpha>0$ ). Second, aggregate growth falls short of individual growth if newborns consume less than existing households because they are less wealthy (i.e. if $A(t)>0$ ) or if there is a pension system which redistributes from the young to the old (i.e. if $\bar{z}_{R}>0$ and thus $\gamma>0$ ). 
Intuitively, $\eta \gamma /\left(r^{F}+\alpha+\beta\right)$ can be interpreted as the per capita deficit of the PAYG pension system, ${ }^{14}$ i.e. the present value of future pension benefits minus tax payments of the current living population, using the annuity rate of interest $r^{F}+\beta$ for discounting. Regardless of the sign of $r^{F}-n_{L}$, the deficit term is positive. In the central case, with $r^{F}>n_{L}$, the group of working-age households experiences the PAYG system as a tax burden on their human capital because they are forced to save at an implicit interest rate $\left(n_{L}\right)$ lower than the market rate of return $\left(r^{F}\right)$. Of course, pensioners no longer pay pension premiums so to these generations the PAYG system adds to human wealth. ${ }^{15}$ The overall effect on $\gamma$ of the PAYG system is positive, i.e. it is equivalent to an implicit government debt left for future disconnected generations (Auerbach and Kotlikoff, 1987, pp. 149-150). For future reference, we note that $\eta \gamma$ is increasing in $\bar{z}_{R}$ and $\pi$ and decreasing in $\eta$ and $\beta$ (see the Appendix).

Aggregate financial wealth is defined as $A(t) \equiv \int_{-\infty}^{t} L(v, t) \bar{a}(v, t) d v$. By differentiating this expression with respect to $t$ and noting that $\bar{a}(t, t)=0$ (as newborns are born without financial wealth) we find an expression for national saving:

$$
\dot{A}(t)=-\beta A(t)+\int_{-\infty}^{t} L(v, t) \dot{\bar{a}}(v, t) d v .
$$

By using (2.3) and (2.8) in (2.26) and simplifying we find:

$$
\dot{A}(t)=r^{F} A(t)+\frac{W I^{N}(t)}{P^{T}(t)}-X(t),
$$

where $W I^{N}(t) / P^{T}(t)$ can be written as:

$$
\frac{W I^{N}(t)}{P^{T}(t)} \equiv\left(\frac{\eta \omega_{0}}{\alpha+\eta}\right)\left(1-t_{L}\right) F_{N}\left[k^{T}(\tau), 1\right] L(t)
$$

and where $F_{N}\left[k^{T}(\tau), 1\right]$ is the marginal product of labour in the traded goods sector (see equation (2.35) below). It follows from (2.27) that aggregate saving, unlike individual saving, does not feature the death rate, $\beta$. The annuity payments are simply transfers, via the life insurance companies, from households which pass away to households who continue to enjoy life.

Aggregate labour supply, measured in efficiency units, is obtained by using (2.6), (2.7), and (2.19):

$$
N(t) \equiv \int_{-\infty}^{t} L(v, t) \bar{n}(v, t) d v=\left(\frac{\eta \omega_{0}}{\alpha+\eta}\right) L(t),
$$

where we have used (2.16) in the final step. Labour supply in efficiency units is proportional to the population. The factor of proportionality depends on labour efficiency at birth $\left(\omega_{0}\right)$ and on the birth rate relative to the rate of decline of labour efficiency $(\eta /(\alpha+\eta))$. Intuitively, if the birth rate is high then the proportionality factor is high as the young productive workers dominate in the effective labour supply.

\footnotetext{
${ }^{14}$ This term was coined by Kotlikoff (1979, p. 240).

${ }^{15}$ In the opposite case, with $r^{F}<n_{L}$, the PAYG system forms a net addition to the human wealth of all current generations.
} 


\section{$2.2 \quad$ Firms}

There are two production sectors in the economy, namely a sector producing internationally traded goods and one producing non-traded goods. Domestic firms in a given sector use capital and (efficiency units of) labour to produce a homogeneous good under constant returns to scale. In view of this assumption, it is appropriate to study representative firms in the two sectors.

Two features of our model warrant further comment. First, in order to obtain nondegenerate capital stock dynamics, we assume that the capital stock is constructed from non-traded goods only. As is pointed out by Turnovsky (1997, p. 104), the rate of investment remains finite in this case because the supply of non-traded goods exhibits increasing marginal costs. ${ }^{16}$ Second, we follow the literature by assuming that both capital and labour are perfectly mobile across sectors and thus attract the same rental rates in both sectors.

\subsubsection{Non-traded sector}

Output in the non-traded sector, $Y^{N}$, is produced according to the technology $Y^{N}(t)=$ $H\left[K^{N}(t), N^{N}(t)\right]$, where $K^{N}$ and $N^{N}$ denote, respectively, capital and efficiency units of labour used in the non-traded goods sector. The production function features constant returns to scale, positive but diminishing marginal products to both factors, and a constant substitution elasticity $\sigma_{N}$. Efficiency units of labour are defined according to $N^{N}(t) \equiv$ $\int_{-\infty}^{t} E(t-v) L^{N}(v, t) d v$, where $L^{N}(v, t)$ is the number of workers of vintage $v$ employed in the non-traded goods sector. The firm rents labour and capital and operating profit is defined as follows:

$$
\Pi^{N}(t) \equiv P^{N}(t) Y^{N}(t)-\int_{-\infty}^{t} W^{N}(v, t) L^{N}(v, t) d v-W^{K}(t) K^{N}(t),
$$

where $W^{K}(t)$ is the rental rate on capital and $W^{N}(v, t)$ denotes the wage for a worker of vintage $v$ at time $t$. The first-order conditions characterizing the firm's optimal plans are:

$$
\begin{aligned}
H_{K}\left[k^{N}(t), 1\right] & =\frac{W^{K}(t)}{P^{N}(t)}, \\
E(t-v) H_{N}\left[k^{N}(t), 1\right] & =\frac{W^{N}(v, t)}{P^{N}(t)},
\end{aligned}
$$

where $k^{N}(t) \equiv K^{N}(t) / N^{N}(t)$ is the capital-effective-labour ratio in the non-traded goods sector. In view of $(2.7)$ and $(2.32)$, it follows that for a given value of $k^{N}(t)$, the real wage

\footnotetext{
${ }^{16}$ Brock and Turnovsky (1994) demonstrate that our emphasis on non-traded investment goods does not entail much loss of generality. In a more general model, with both types of goods acting as components of a composite investment good, the fundamental dynamic characteristics of the model are essentially the same as in the present model. With traded (components of) investment goods, and in the absence of firm-level adjustment costs, the capital stock can jump so the (derivative) dynamics of the current account is different than in our model.
} 
rate declines exponentially with the age of the worker. Since technology features constant returns to scale, factor payments exhaust revenue and pure profits are zero $\left(\Pi^{N}(t)=0\right)$.

\subsubsection{Traded sector}

The specification of the traded sector is similar to that in the non-traded sector. Technology is given by $Y^{T}(t)=F\left[K^{T}(t), N^{T}(t)\right]$, where $Y^{T}, K^{T}$, and $N^{T}$ denote, respectively, output, capital, and efficiency units of labour in the traded goods sector. We denote the constant substitution elasticity of the production function by $\sigma_{T}$. Labour in efficiency units is defined as $N^{T}(t) \equiv \int_{-\infty}^{t} E(t-v) L^{T}(v, t) d v$, where $L^{T}(v, t)$ is the number of workers of vintage $v$ employed in the traded goods sector. Profit in this sector is given by:

$$
\Pi^{T}(t) \equiv P^{T}(t) Y^{T}(t)-\int_{-\infty}^{t} W^{N}(v, t) L^{T}(v, t) d v-W^{K}(t) K^{T}(t),
$$

where we have incorporated the assumption that capital and labour are mobile across sectors (i.e. $W^{N}(v, t)$ and $W^{K}(t)$ are the same in $(2.30)$ and $\left.(2.33)\right)$. The first-order conditions are given by:

$$
\begin{aligned}
F_{K}\left[k^{T}(t), 1\right] & =\frac{W^{K}(t)}{P^{T}(t)}, \\
E(t-v) F_{N}\left[k^{T}(t), 1\right] & =\frac{W^{N}(v, t)}{P^{T}(t)},
\end{aligned}
$$

where $k^{T}(t) \equiv K^{T}(t) / N^{T}(t)$ is the capital-effective-labour ratio in the traded goods sector. Pure profits are zero $\left(\Pi^{T}(t)=0\right)$.

\subsection{Portfolio investments}

There are three assets in the economy, namely (claims on) domestic capital goods, domestic government bonds, and foreign bonds. We look at these assets in turn. The portfolio investor chooses its capital accumulation decision by maximizing the present value of cash flows from its capital stock. This cash flow (expressed in terms of non-traded goods) is given by:

$$
\frac{V^{N}(t)}{P^{N}(t)}=\int_{t}^{\infty}\left[\left(\frac{W^{K}(\tau)}{P^{N}(\tau)}\right) K(\tau)-I^{N}(\tau)\right] e^{-R^{N}(t, \tau)} d \tau
$$

where $I^{N}$ is gross investment (consisting of non-traded goods) and $R^{N}(t, \tau) \equiv \int_{t}^{\tau} r^{N}(s) d s$ is a discounting factor. The capital accumulation identity is:

$$
\dot{K}(\tau)=I^{N}(\tau)-\delta K(\tau)
$$

where $\delta>0$ is the constant depreciation rate of capital. The investor chooses paths for gross investment and the capital stock in order to maximize (2.36) subject to (2.37) and taking as 
given the initial capital stock $(K(t))$ and the path of the rental rate $\left(W^{K}(\tau)\right)$. The first-order condition for this optimization problem is:

$$
\frac{W^{K}(t)}{P^{N}(t)}=r^{N}(t)+\delta
$$

It is not difficult to show that $V^{N}(t)=P^{N}(t) K(t)$.

Government bonds are denominated in terms of non-traded goods and carry a real yield of $r^{G}(t)$. Portfolio investors are indifferent between government bonds and physical capital if (and only if) they attract the same rate of return:

$$
r^{G}(t)=r^{N}(t)
$$

Foreign bonds are denominated in terms of traded goods and carry a real yield of $r^{F}$ (fixed in world markets and exogenous to domestic investors). Portfolio investors are indifferent between, on the one hand foreign bonds and, on the other hand, domestic capital and government bonds if (and only if) their rates of return (measured in the same units) are equalized. This furnishes the final no-arbitrage condition:

$$
r^{N}(t)=r^{F}+\frac{\dot{P}^{T}(t)}{P^{T}(t)}-\frac{\dot{P}^{N}(t)}{P^{N}(t)}
$$

\subsection{Loose ends}

The sectoral allocation of labour and capital services is as follows. Since both factors are perfectly mobile across sectors it follows that they attract the same rental rates. Indeed, by using (2.32) and (2.35) for labour, and (2.31) and (2.34) for capital we obtain:

$$
\begin{aligned}
W^{N}(t)\left[\equiv \frac{W^{N}(v, t)}{E(t-v)}\right] & =P^{N}(t) H_{N}\left[k^{N}(t), 1\right]=P^{T}(t) F_{N}\left[k^{T}(t), 1\right] \\
W^{K}(t) & =P^{N}(t) H_{K}\left[k^{N}(t), 1\right]=P^{T}(t) F_{K}\left[k^{T}(t), 1\right]
\end{aligned}
$$

where $W^{N}(t)$ is the wage rate per efficiency unit of labour.

Since government bonds are denominated in terms of non-traded goods, the government budget identity is given by:

$$
\dot{A}^{G}(t)=r^{N}(t) A^{G}(t)+\frac{P^{T}(t) G^{T}(t)}{P^{N}(t)}+G^{N}(t)-\frac{t_{L}(t) W^{N}(t) N(t)}{P^{N}(t)},
$$

where $r^{N}(t)$ denotes the real rate of interest on government bonds (see (2.39)), $A^{G}$ is aggregate government debt, and $G^{i}$ is government consumption of sector- $i$ goods. The government solvency condition is:

$$
\lim _{\tau \rightarrow \infty} A^{G}(\tau) e^{-R^{N}(t, \tau)}=0 .
$$


Combining (2.43) and (2.44) yields the government intertemporal budget constraint:

$$
A^{G}(t)=\int_{t}^{\infty}\left[\frac{t_{L}(\tau) W^{N}(\tau) N(\tau)-P^{T}(\tau) G^{T}(\tau)}{P^{N}(\tau)}-G^{N}(\tau)\right] e^{-R^{N}(t, \tau)} d \tau .
$$

To the extent that there is outstanding debt (positive left-hand side), this must be matched by the present value of present and future primary surpluses (positive right-hand side).

Note that the PAYG pension system does not affect the government financial accounts (as represented in (2.43) and (2.45)) because it is run on a balanced-budget basis, i.e. $\bar{t}_{W}$ and $\bar{z}_{R}$ are such that:

$$
\bar{t}_{W}\left(1-e^{-\eta \pi}\right) L(t)=\bar{z}_{R} e^{-\eta \pi} L(t)
$$

where the left-hand side of (2.46) represents total pension payments by the young, and the right-hand side is total pension receipts by the old. In this paper we follow Nielsen (1994) and restrict attention to the defined-benefit case, i.e. following any shock in $\eta$ or $\pi, \bar{z}_{R}$ is held constant and the pension budget is balanced by an adjustment in $\bar{t}_{W} \cdot{ }^{17}$

Foreign bonds are denominated in terms of traded goods. The current account is thus:

$$
\dot{A}^{F}(t)=r^{F} A^{F}(t)+Y^{T}(t)-C^{T}(t)-G^{T}(t),
$$

where $A^{F}(t)$ denotes the stock of foreign bonds in the hands of domestic households.

The model is closed by the clearing conditions in, respectively, the labour market, the capital rental market, and the non-traded goods market:

$$
\begin{aligned}
N(t) & =N^{N}(t)+N^{T}(t), \\
K(t) & =K^{N}(t)+K^{T}(t), \\
Y^{N}(t) & =C^{N}(t)+I^{N}(t)+G^{N}(t) .
\end{aligned}
$$

The country is small in world markets and faces a given price for traded goods. We can thus set:

$$
P^{T}(t)=1, \quad \frac{\dot{P}^{T}(t)}{P^{T}(t)}=0, \quad \text { for all } t,
$$

so that $P^{N}(t)$ represents the real exchange rate. An increase in $P^{N}$ will be referred to a real appreciation.

\section{$2.5 \quad$ Full model}

In the presence of non-zero population growth, the model gives rise to ongoing economic growth. In order to study the growth process, we rewrite the model in a stationary format by expressing all growing variables in per capita terms. The key equations of the full model

\footnotetext{
${ }^{17}$ Note that (2.46) has already been incorporated in (2.25).
} 
are stated in Table 1, whilst the variable definitions are stated in Table 2. The endogenous variables are $P^{N}, W^{N}, W^{K}, k, n, x, a, a^{F}, \gamma, \Delta, \omega_{N}, P_{C}, k^{i}, n^{i}, y^{i}, c^{i}$ (for $i=N, T$ ). The exogenous variables are $g^{i}$ (for $i=N, T$ ), $r^{F}, a^{G}, \beta, \eta, \pi, \bar{z}_{R}$, and $t_{L} \cdot{ }^{18}$ We demonstrate below that the model is saddle-point stable, with two predetermined state variables $(k$ and $\left.a^{F}\right)$ and three non-predetermined "jumping" state variables $\left(P^{N}, x\right.$, and $\left.\Delta\right)$.

We briefly discuss the equations in Table 1, starting with the dynamic ones. Equation (T1.1) is obtained by combining (2.38) and (2.40). Intuitively, equation (T1.1) says that the instantaneous return on non-traded capital (consisting of a rental payment plus an appreciation term) must equal the rate of return on a traded bond. The real exchange rate thus plays a dual role: it must clear the non-traded goods market and it serves as an asset price (Turnovsky, 1997, p. 112). Equation (T1.2) is the accumulation equation for the per capita stock of capital. It is obtained by combining (2.37) and (2.50). Equation (T1.3) shows the optimum time path of per capita full consumption. It is obtained by expressing (2.24) in per capita format. Equation (T1.4) is the macroeconomic accumulation equation for per capita net foreign assets and is obtained by expressing (2.47) in per capita format. Finally, equation (T1.5), describing the dynamic behaviour of $\Delta(t)$, is obtained by differentiating (2.10) with respect to time.

Equations (T1.6)-(T1.20) are essentially static equations, in the sense that they can be related uniquely to the endogenous state variables and the exogenous variables of the model. Equations (T1.6) and (T1.7) are the intensive-form production functions in, respectively, the traded and non-traded sector. ${ }^{19}$ Equations (T1.8)-(T1.9) are obtained by rewriting the expressions in (2.41) in the intensive form. Similarly, equations (T1.10)-(T1.11) are obtained from (2.42). Equations (T1.12) and (T1.13) are obtained from, respectively, (2.48) and (2.49). Equation (T1.14) is (2.29) in per capita form. Equations (T1.15)-(T1.16) and (T1.18) are obtained from, respectively, (2.13)-(2.14) and (2.4). Finally, equation (T1.17) is identical to (2.25). Of course, in various places we have incorporated the normalization (2.51).

\subsection{Main properties}

Before turning to the dynamic analysis of the model, we first characterize its steady state. We denote steady-state values of endogenous variables by a hat $\left(^{\wedge}\right)$. By imposing the steady state in (T1.1) and noting (T1.11) we find that the foreign interest rate pins down a unique

${ }^{18}$ The government budget identity can be written in per capita terms as follows:

$$
\dot{a}^{G}(t)=r^{F}-n_{L}-\frac{\dot{P}^{N}(t)}{P^{N}(t)} a^{G}(t)+\frac{g^{T}(t)-t_{L}(t) W^{N}(t) n(t)}{P^{N}(t)}+g^{N}(t) .
$$

It is used either in its static form (by setting $\dot{a}^{G}(t)=0$ and assuming that the lump-sum labour income tax balances the budget) or in its dynamic form by imposing the (suitably modified) government solvency condition (2.44).

${ }^{19}$ The reader is reminded of the key properties of the intensive-form production functions: $f \equiv F k^{T}, 1$, $F_{K}=f^{\prime}, F_{N}=f-k^{T} f^{\prime}, h \equiv H \quad k^{N}, 1, H_{K}=h^{\prime}$, and $H_{N}=h-k^{N} h^{\prime}$. 
Table 1: Short-run version of the model $^{(\sharp)}$

(a) Dynamic equations:

$$
\begin{aligned}
\frac{\dot{P}^{N}(t)}{P^{N}(t)} & =r^{F}+\delta-\frac{W^{K}(t)}{P^{N}(t)} \\
\dot{k}(t) & =n^{N}(t) y^{N}(t)-c^{N}(t)-g^{N}(t)-\left(\delta+n_{L}\right) k(t) \\
\dot{x}(t) & =\left[\sigma_{U}\left(r^{F}-\rho\right)+\alpha+\left(1-\sigma_{U}\right) \frac{\dot{P}_{C}(t)}{P_{C}(t)}\right] x(t)-\frac{\eta \gamma+(\alpha+\eta) a(t)}{\Delta(t)} \\
\dot{a}^{F}(t) & =\left(r^{F}-n_{L}\right) a^{F}(t)+n^{T}(t) y^{T}(t)-c^{T}(t)-g^{T}(t) \\
\dot{\Delta}(t) & =-1+\left[\left(1-\sigma_{U}\right)\left(r^{F}+\beta-\frac{\dot{P}_{C}(t)}{P_{C}(t)}\right)+\sigma_{U}(\rho+\beta)\right] \Delta(t)
\end{aligned}
$$

(b) Static equations:

$$
\begin{aligned}
y^{T}(t) & =f\left[k^{T}(t)\right] \\
y^{N}(t) & =h\left[k^{N}(t)\right] \\
W^{N}(t) & =f\left[k^{T}(t)\right]-k^{T}(t) f^{\prime}\left[k^{T}(t)\right] \\
W^{N}(t) & =P^{N}(t)\left[h\left[k^{N}(t)\right]-k^{N}(t) h^{\prime}\left[k^{N}(t)\right]\right] \\
W^{K}(t) & =f^{\prime}\left[k^{T}(t)\right] \\
W^{K}(t) & =P^{N}(t) h^{\prime}\left[k^{N}(t)\right] \\
n(t) & =n^{T}(t)+n^{N}(t) \\
k(t) & =n^{T}(t) k^{T}(t)+n^{N}(t) k^{N}(t) \\
n(t) & =\frac{\eta \omega_{0}}{\alpha+\eta} \\
c^{T}(t) & =\left[1-\omega_{N}(t)\right] x(t) \\
P^{N}(t) c^{N}(t) & =\omega_{N}(t) x(t) \\
\gamma & =\left(\frac{e^{-\beta \pi}}{1-e^{-\eta \pi}}\right)\left(\frac{\bar{z}_{R}}{r^{F}+\beta}\right)\left(r^{F}+\alpha+\beta\right)\left(\frac{e^{-r^{F}}-e^{-n_{L} \pi}}{n_{L}-r^{F}}\right) \\
a(t) & =P^{N}(t)\left[k(t)+a^{G}(t)\right]+a^{F}(t)
\end{aligned}
$$

(c) Miscellaneous equations:

$$
\begin{aligned}
\omega_{N}(t) & \equiv\left(1-\varepsilon_{C}\right)^{\sigma_{C}}\left(\frac{P^{N}(t)}{P_{C}(t)}\right)^{1-\sigma_{C}} \\
P_{C}(t) & \equiv \begin{cases}{\left[\left(\varepsilon_{C}\right)^{\sigma_{C}}+\left(1-\varepsilon_{C}\right)^{\sigma_{C}}\left[P^{N}(t)\right]^{1-\sigma_{C}}\right]^{1 /\left(1-\sigma_{C}\right)}} & \text { for } \sigma_{C} \neq 1 \\
\left(\frac{1}{\varepsilon_{C}}\right)^{\varepsilon_{C}}\left(\frac{P^{N}(t)}{1-\varepsilon_{C}}\right)^{1-\varepsilon_{C}} & \text { for } \sigma_{C}=1\end{cases}
\end{aligned}
$$

$(\sharp)$ See Table 2 for the variable definitions. 
Table 2: Key variable definitions

$y^{i} \quad$ output per efficiency unit of labour in sector $i(i=N, T)$

$k^{i} \quad$ capital per efficiency unit of labour in sector $i(i=N, T)$

$k \quad$ per capita capital stock

$n^{i} \quad$ per capita efficiency units of labour in sector $i(i=N, T)$

$n \quad$ per capita labour supply in efficiency units of labour

$P^{N} \quad$ product price in non-traded sector (real exchange rate)

$W^{N} \quad$ rental rate on efficiency units of labour

$W^{K} \quad$ rental rate on capital

$r^{F} \quad$ world real interest rate

a per capita real financial wealth

$a^{G} \quad$ per capita government debt

$a^{F} \quad$ per capita foreign bonds

$x \quad$ per capita full consumption

$\bar{t}_{W} \quad$ real lump-sum tax paid by working-age households

$\bar{z}_{R} \quad$ real lump-sum transfer received by retired households

$c^{i} \quad$ per capita household consumption of sector- $i$ goods $(i=N, T)$

$g^{i} \quad$ per capita government consumption of sector- $i$ goods $(i=N, T)$ 
capital intensity in the non-traded sector, i.e. $r^{F}+\delta=h^{\prime}\left[\hat{k}^{N}\right]$. Equations (T1.8)-(T1.10) then determine unique values for $\hat{k}^{T}, \hat{W}^{N}, \hat{W}^{K}$, and $\hat{P}^{N}$ as a function of $\hat{k}^{N}$ (and thus ultimately of $\left.r^{F}+\delta\right)$. It follows from (T1.6)-(T1.7) that $\hat{y}^{T}$ and $\hat{y}^{N}$ are constant, and from (T1.19)-(T1.20) that $\hat{\omega}_{N}$ and $\hat{P}_{C}$ are constant in the steady state. The long-run factor price frontier thus imposes a lot of fixity into the model.

Given the above considerations it should come as no surprise that demand shocks (such as an increase in government consumption), demographic shocks (such as changes in $\eta$ or $\beta$ ), or pension shocks (changes in $\pi$ or $\bar{z}_{R}$ ) will exert no long-run effect on $\hat{k}^{N}, \hat{k}^{T}, \hat{y}^{N}, \hat{y}^{T}$, $\hat{W}^{N}, \hat{W}^{K}, \hat{P}^{N}, \hat{\omega}_{N}$ and $\hat{P}_{C} \cdot{ }^{20}$ Such shocks may, of course, have temporary effects on these variables provided the domestic interest rate deviates from the exogenous foreign interest rate during transition.

The model possesses non-trivial transitional dynamics. There are two predetermined state variables ( $k$ and $a^{F}$ ) and three non-predetermined "jumping" state variables $\left(P^{N}, x\right.$, and $\left.\Delta\right)$. The following proposition summarizes our main findings regarding transitional dynamics.

Proposition 1 Consider the model of Table 1 and assume that $\sigma_{U}\left(r^{F}-\rho\right)<\eta$. The following results can be established: (i) the model is locally saddle-point stable, i.e. the Jacobian matrix features two negative (stable) characteristic roots and three positive (unstable) roots; (ii) the capital stock features smooth transitional dynamics; (iii) there is no transitional dynamics in the real exchange rate if the traded goods sector is relatively capital intensive $\left(k^{T}>k^{N}\right)$; (iv) the real exchange rate features non-trivial transitional dynamics if the non-traded sector is relatively capital intensive $\left(k^{N}>k^{T}\right)$; $(v)$ the long-run growth rate in the economy is equal to $n_{L} \equiv \eta-\beta$.

Proof: see Bettendorf and Heijdra (2004).

Perhaps the most interesting aspect of this proposition is the fact that the qualitative shape of the adjustment path for the real exchange rate depends critically on the relative capital intensity in the traded and non-traded sectors. This property was also noted by Turnovsky (1997, p. 112) in the context of a representative-agent model. ${ }^{21}$

\footnotetext{
${ }^{20} \mathrm{~A}$ productivity shock in either of the two productive sectors will, of course, affect these variables. See Turnovsky (1997, pp. 105-123) for an extensive analysis of these points in the context of a model with an infinitely-lived representative agent.

${ }^{21}$ Bond, Wang, and Yip (1996) show that the factor intensity condition similarly affects the transitional dynamics in the relative price of human capital in the closed-economy two-sector endogenous growth model with physical and human capital.
} 


\section{The core model}

\subsection{Benchmark}

The model in Table 1 is too complex to characterize analytically the impulse-response functions associated with changes in demographic and pension-related variables. For that reason we focus in the remainder of this paper on a benchmark case with the following key features. First, we assume that the traded sector is relatively capital intensive (i.e. $k^{T}>k^{N}$ ). This is a rather natural assumption to make in view of the fact that a large part of the output of the non-traded sector consists of labour-intensive services. Furthermore, this case provides additional analytical simplifications, in that there is no transitional dynamics in the real exchange rate (see Proposition 1(iii) above). Second, to avoid unnecessary mathematical complications, we set the various substitution elasticities appearing in the model equal to unity, i.e. $\sigma_{U}=\sigma_{C}=\sigma_{N}=\sigma_{T}=1 .{ }^{22}$ Third, in order to avoid having to go through a whole taxonomy of cases admitted by our model, we restrict attention to the case which we find empirically most relevant. In particular, we assume that households are relatively patient $\left(r^{F}>\rho\right)$ and that the rate of population growth is relatively low $\left(r^{F}>n_{L}\right)$.

The core model can be solved sequentially as follows. First, we can use (T1.8)-(T1.13) to derive the following quasi-reduced-form expressions for $W^{K} / P^{N}, W^{N}, n^{N}$ and $y^{N}$ :

$$
\begin{aligned}
& \frac{W^{K}(t)}{P^{N}(t)}=\omega^{K}\left[P^{N}(t)\right], \\
& W^{N}(t)=W^{N}\left[P^{N}(t)\right], \\
& n^{N}(t)=n-n^{T}(t)=n^{N}[P_{+}^{N}(t), \underbrace{\left.(t), n_{+}\right]}_{-}, \\
& y^{N}(t)=y^{N}\left[P^{N}(t)\right],
\end{aligned}
$$

where the signs of the partial derivatives are as indicated. ${ }^{23}$

Using (3.1) in (T1.1) we find the following differential equation for the real exchange rate:

$$
\frac{\dot{P}^{N}(t)}{P^{N}(t)}=r^{F}+\delta-\omega^{K}\left[P^{N}(t)\right]
$$

\footnotetext{
${ }^{22}$ These simplifications do not affect any of the qualitative conclusions of this section. Since there is no transitional dynamics in the real exchange rate $\left(\dot{P}^{N}=0\right)$, it follows that $\dot{P}_{C}=\dot{\Delta}=\dot{\omega}_{N}=0$ so that $\sigma_{U}$ and $\sigma_{C}$ cannot play a role. The technological substitution elasticities $\left(\sigma_{N}\right.$ and $\left.\sigma_{T}\right)$ only affect the adjustment speed in the economy, but not the qualitative shape of the adjustment path, which is fully characterized by the factor intensity assumption.

${ }^{23}$ The intuition behind these effects is well known from two-sector trade theory - see, e.g., Woodland (1982, ch. 4). First, since the number of goods equals the number of factors, factor prices are independent of factor supplies (factor price equalization). Second, an increase in $P^{N}$ will increase the return to the factor used intensively in the non-traded sector (labour) and decrease the return on the other factor (Stolper-Samuelson Theorem). Third, ceteris paribus $P^{N}$, an increase in the supply of a factor will lead to an increase in the output of the commodity that uses that factor intensively and a decrease in the output of the other good (Rybczynski Theorem).
} 
Since $\partial \omega^{K} / \partial P^{N}<0$, equation (3.5) is an unstable differential equation for which the only economically sensible solution is the steady-state solution, i.e. it follows that $\dot{P}^{N}(t)=0$ and $P^{N}(t)=\hat{P}^{N}$ for all $t$.

In the second step we exploit the constancy of the real exchange rate and write the remainder of the core model in the following parsimonious system of first-order differential equations:

$$
\begin{aligned}
\dot{k}(t) & =n^{N}\left[\hat{P}^{N}, k(t), n\right] \hat{y}^{N}-\left(1-\varepsilon_{C}\right) x(t) / \hat{P}^{N}-g^{N}-\left(\delta+n_{L}\right) k(t), \\
\dot{x}(t) & =\left(r^{F}-\rho+\alpha\right) x(t)-(\rho+\beta)[\eta \gamma+(\alpha+\eta) a(t)], \\
\dot{a}(t) & =\left(r^{F}-n_{L}\right) a(t)-x(t)+\left(1-t_{L}\right) \hat{W}^{N} n .
\end{aligned}
$$

Equations (3.6) and (3.7) are the simplified versions of, respectively, (T1.2) and (T1.3). Equation (3.8) is the dynamic expression for total financial wealth. ${ }^{24}$ The dynamic properties of the core model can be illustrated with the aid of Figure 1. In the bottom panel, the $\dot{k}(t)$ line is the graphical representation of equation (3.6), holding constant the level of full consumption. In view of the fact that $\partial n^{N} / \partial k<0$, the $\dot{k}(t)$ line is downward sloping and the capital dynamics is stable and non-degenerate.

In the top panel of Figure 1, the equilibrium loci associated with the simultaneous system (3.7)-(3.8) have been drawn. Since we assume that $r^{F}>\rho$, it follows from (3.7) that the $\dot{x}(t)=0$ line is upward sloping, and that $\partial \dot{x} / \partial x>0$, i.e. the vertical arrows point away from the $\dot{x}(t)=0$ line. Also, since we assume that $r^{F}>n_{L}$, the $\dot{a}(t)=0$ line is also upward sloping, and $\partial \dot{a} / \partial a>0$, i.e. the horizontal arrows point away from the $\dot{a}(t)=0$ line. It is easy to verify that the subsystem is saddle-point stable provided the $\dot{x}(t)=0$ line is steeper than the $\dot{a}(t)=0$ line. ${ }^{25}$

Armed with the graphical apparatus of Figure 1, we can now investigate the impact, transitional, and long-run effects of various shocks in demographic and pension-related variables. In all these shocks we hold the per capita debt level of the government constant $\left(\dot{a}^{G}(t)=0\right)$ and assume that the labour income tax balances the budget.

\subsection{Demographic shocks}

In this sub-section we study the macroeconomic effects of demographic shocks. To keep things simple, we abstract from a pre-existing pension system, i.e. we set $\bar{z}_{R}=0$ so that $\gamma=0$ in the

\footnotetext{
${ }^{24}$ It is obtained by differentiating (T1.18) with respect to time and using the various expressions for $\dot{P}^{N}(t)$, $\dot{k}(t), \dot{a}^{F}(t), \dot{a}^{G}(t)$, as well as the zero-profit conditions in the two sectors.

${ }^{25}$ The determinant of the Jacobian matrix equals:

$$
\begin{aligned}
|J| & \equiv r^{F}-\eta+\beta \quad r^{F}-\rho+\alpha-(\rho+\beta)(\alpha+\eta) \\
& =r^{F}-\eta-\rho \quad r^{F}+\alpha+\beta .
\end{aligned}
$$

It follows that $r^{F}-\rho-\eta<0$ is a necessary (and sufficient) stability condition. See also Proposition 1 , specialized for the case $\sigma_{U}=1$.
} 

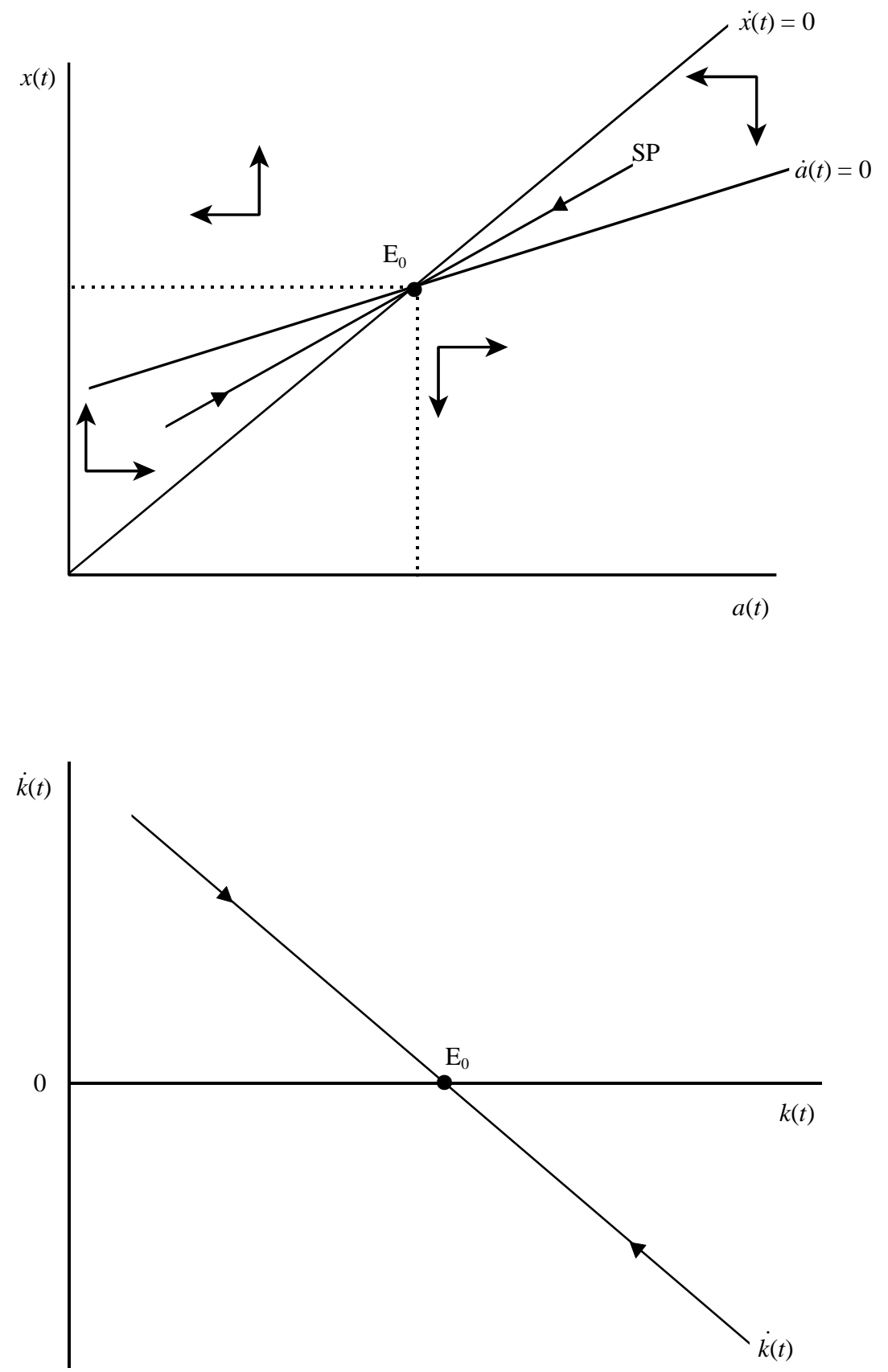

Figure 1: Stability in the Core Model 
dynamic equation for full consumption - see equation (3.7) above. Changes in demographic parameters cause quite diverse effects on the structure of the economy. For example, a change in the birth rate $(\eta)$ has three separate effects. First, it changes the generational turnover term and thus affects the modified Euler equation for full consumption (3.7). Second, it leads to a change in the population growth rate $\left(n_{L} \equiv \eta-\beta\right)$, which in turn affects both the net investment equation (3.6) and the asset accumulation equation (3.8). Third, with agedependent labour productivity $(\alpha>0)$, it changes the macroeconomic participation rate - see equation (T1.14) above. This, in turn, affects both the sectoral allocation of labour $\left(n^{N}\right.$ and $\left.n^{T}\right)$ and the aggregate level of wage income $\left(\hat{W}^{N} n\right)$. In contrast, a change in the death probability $(\beta)$ affects population growth and the generational turnover term, but leaves the macroeconomic participation rate unchanged.

For purposes of exposition we abstract from age-dependent labour productivity in this sub-section (by setting $\alpha=0$ ) and study composite demographic shocks. This approach allows us to study in isolation the macroeconomic effects of (a) changes in the generational turnover term and (b) changes in the population growth rate.

\subsubsection{Generational turnover}

The first composite demographic shock we consider is an equal decline in the birth rate and the death probability, i.e. $d \eta=d \beta<0$. The population growth rate is unaffected $\left(d n_{L}=0\right)$, but the generational turnover term appearing in (3.7) increases. The impact, transitional, and long-run effects of the shock have been illustrated in Figure 2. The initial equilibrium is at point $\mathrm{E}_{0}$ in the two panels. As a result of the shock, the $\dot{x}(t)=0$ rotates in a clockwise fashion, from $[\dot{x}(t)=0]_{\text {old }}$ to $[\dot{x}(t)=0]_{\text {new }}$, but the $\dot{a}(t)=0$ line remains in the same position because nothing has happened to the population growth rate (by construction) or the macroeconomic participation rate (because $\alpha=0$ ). At impact, the economy jumps from $\mathrm{E}_{0}$ to point $\mathrm{A}$ on the new saddle path SP. Intuitively, the fall in full consumption at impact results from the interplay of two opposing effects. ${ }^{26}$ On the one hand, human wealth rises due the fact that the annuity rate of interest, $r^{F}+\beta$, falls so that the present value of after-tax wages increases. On the other hand, all households expect to live longer lives and thus reduce the marginal propensity to consume out of total wealth on that account. The latter effect dominates the former effect so that full consumption falls.

In the bottom panel of Figure 2, the capital accumulation line shifts up at impact, from $[\dot{k}(t)]_{\text {old }}$ to $[\dot{k}(t)]_{\text {impact }}$, because consumption of non-traded goods declines. The output in the non-traded sector which is thus freed up leads to net capital accumulation, i.e. $\dot{k}(t)>0$

\footnotetext{
${ }^{26}$ Recall that for the case under consideration, full consumption can be written as: $x(t)=(\rho+\beta) a(t)+a^{H}(t)$.

At impact, financial assets are predetermined (since $\dot{P}^{N}(t)=0$ precludes asset revaluation effects) so that the impact change in full consumption results from the changes in $\rho+\beta$ and in $a^{H}$.
} 
at point $\mathrm{A}$.

During transition the economy gradually moves from point $\mathrm{A}$ to point $\mathrm{E}_{1}$ in the top panel. Full consumption and financial assets both increase over time. Consumption of non-tradeable goods gradually rises and in the bottom panel of Figure 2 the capital accumulation line starts to shift to the left (not drawn). This slows down net capital accumulation and, as time evolves, the capital stock even starts to decline.

In the new steady state the economy settles at point $E_{1}$ in the two panels of Figure 2. Both full consumption and financial assets increase, but the domestic capital stock decreases in the long run. It follows (from (T1.18) above) that the stock of net foreign assets also increases in the long run. We summarize the results in the following propositions.

Proposition 2 Consider the core model (with $\alpha=\gamma=0$ ) and assume that $d \eta=d \beta<0$. The following results can be established: (i) at impact, $x, c^{T}$, and $c^{N}$ fall, $a, k$, and $a^{F}$ are unchanged, and $\dot{x}$ and $\dot{k}$ increase; (ii) during transition, $x, c^{T}$, and $c^{N}$ rise monotonically, but following its initial increase, $k$ starts to decline during the later phases of adjustment; (iii) in the new steady state, $x, c^{T}, c^{N}$ and $a^{F}$ are all increased, but $k$ is decreased; (iv) the path for per capita output in the traded (non-traded) sector is qualitatively the same as (the opposite of) the path for $k$; (v) real per capita GDP is defined as $y(t) \equiv \hat{W}^{N} n+\hat{W}^{K} k(t)$ and its path is proportional to the path for $k$; (vi) the long-run growth rate in the economy is unchanged.

Proof: see text and Bettendorf and Heijdra (2004).

\subsubsection{Population growth}

The second composite demographic shock consists of a decline in the birth rate combined with an increase in the death probability such that the generational turnover effect is unchanged. It follows from (3.7) that the shock is such that $-\eta d \beta=(\rho+\beta) d \eta<0$ so that $\eta d n_{L}=$ $(\eta+\rho+\beta) d \eta<0$. In Figure 3 we illustrate the macroeconomic effects of such a decline in the population growth rate. As a result of the shock, the $[\dot{a}(t)=0]$ line rotates in a counter-clockwise fashion, from $[\dot{a}(t)=0]_{\text {old }}$ to $[\dot{a}(t)=0]_{\text {new }}$, but the $[\dot{x}(t)=0]$ line remains in the same position because (by construction) the generational turnover effect is unchanged. At impact, the economy jumps onto the new saddle path SP and consumption is increased. Though per capita human wealth falls (due to the higher annuity rate of interest, $r^{F}+\beta$ ), the shorter expected lifetime induces agents to increase their propensity to consume out of total wealth, $\rho+\beta$. Since the latter effect dominates the former, full consumption increases at impact.

In the bottom panel of Figure 3, there are two mechanisms affecting the position of the $\dot{k}(t)$ line. On the one hand, the impact increase in consumption of non-traded goods crowds out net investment and shifts the $\dot{k}(t)$ line in a downward direction. On the other hand, the 

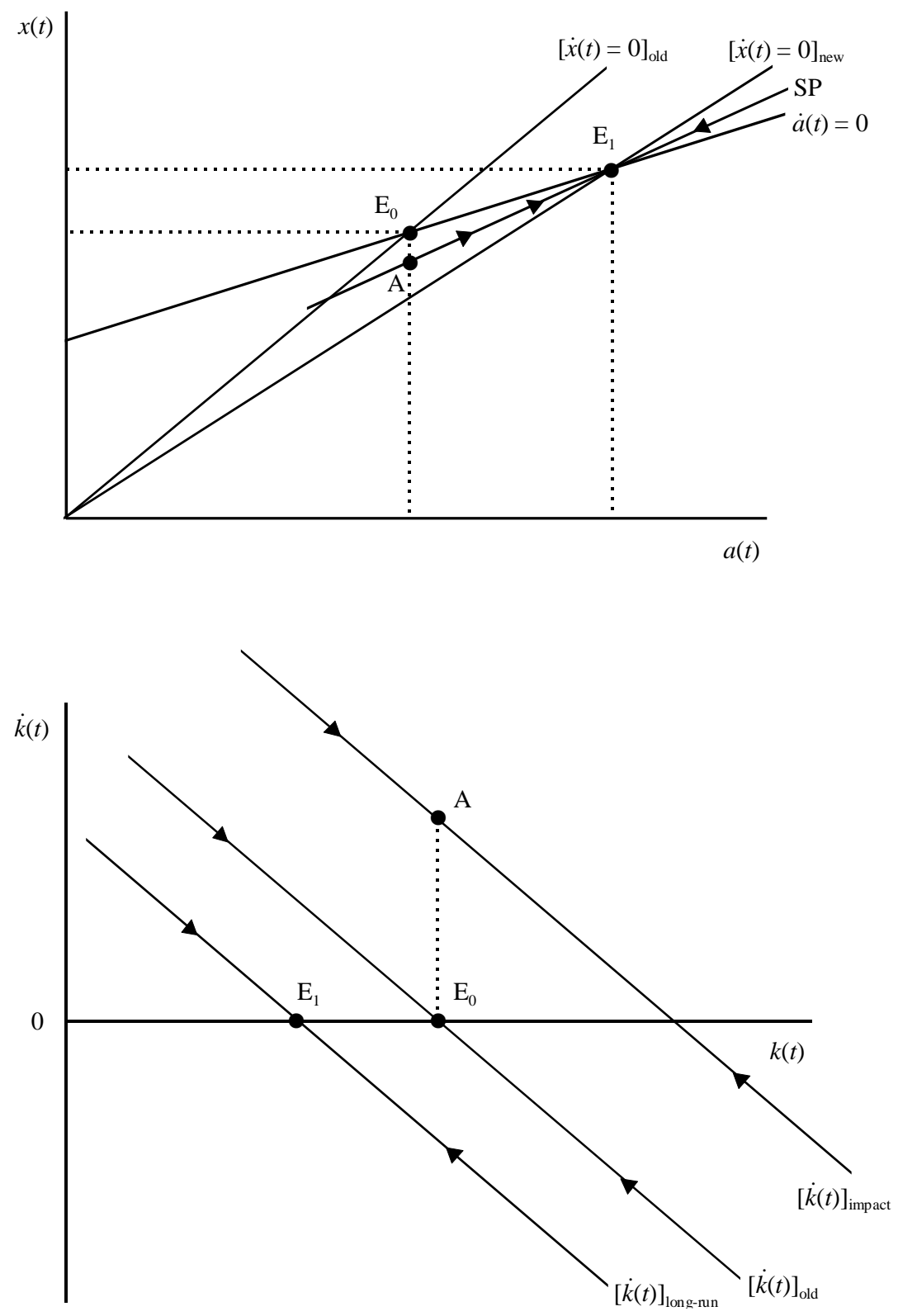

Figure 2: Generational-Turnover Effect 
decline in the population growth rate makes room for additional net investment (an upward shift). We show in the Appendix that the following condition can be derived for the impact effect on net investment: ${ }^{27}$

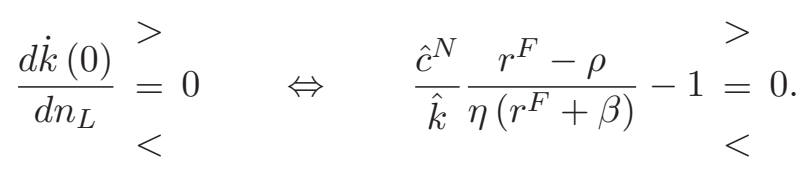

In Figure 3 we have drawn the case for which the crowding-out effect is relatively small, so that the $\dot{k}(t)$ line shifts to the right at impact. At point A, the per capita stock of capital starts to increase gradually.

During transition, the economy gradually moves from $\mathrm{A}$ to point $\mathrm{E}_{1}$ in the top panel of Figure 3. Full consumption and financial assets both increase. The increase in full consumption gradually shifts the $\dot{k}(t)$ line to the left as consumption of non-traded goods crowds out net investment, i.e. $\dot{k}(t)<0$ there.

In the long run, the economy settles at point $\mathrm{E}_{1}$ in the two panels of Figure 3 . The longrun effect on the capital stock is theoretically ambiguous but the following condition can be derived:

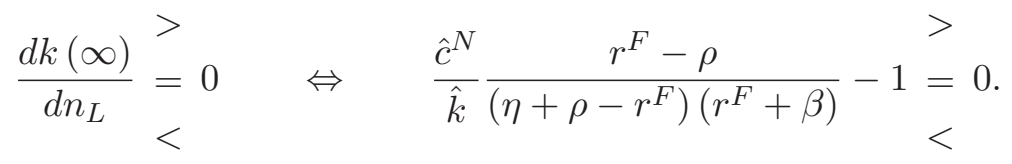

The crowding-out effect is stronger in the long-run than at impact (since $r^{F}>\rho$ ) and in Figure 3 we have drawn the case for which the per capita stock of capital falls in the long run. For convenience we summarize the results in a proposition. ${ }^{28}$

Proposition 3 Consider the core model (with $\alpha=\gamma=0$ ) and assume that $-\eta d \beta=(\rho+\beta) d \eta<$ 0 so that $\eta d n_{L}=(\eta+\rho+\beta) d \eta<0$. The following results can be established: (i) at impact, $x, c^{T}$, and $c^{N}$ rise, $a, k$, and $a^{F}$ are unchanged, $\dot{x}$ increases and $\dot{k}$ increases (decreases) if the $\hat{c}^{N} / \hat{k}$ ratio is low (high) (see (3.9)); (ii) during transition, $x, c^{T}$, and $c^{N}$ rise monotonically, but provided $\hat{c}^{N}$ is strictly positive, the adjustment path for $k$ may be non-monotonic; (iii) in the new steady state, $x, c^{T}$, and $c^{N}$ are all increased, and $k$ is increased (decreased) if the $\hat{c}^{N} / \hat{k}$ ratio is low (high) (see (3.10)); (iv) the long-run growth rate in the economy falls.

Proof: see text and Bettendorf and Heijdra (2004).

\footnotetext{
${ }^{27}$ In the special case, for which $a^{G}=a^{F}=0$ initially, this condition can be further simplified to:

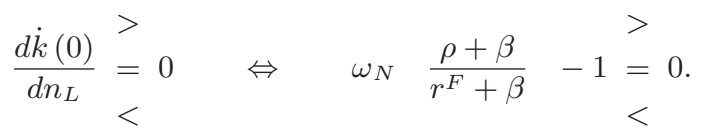

${ }^{28}$ Of course, items (iv)-(v) of Proposition 2 are also still valid.
} 

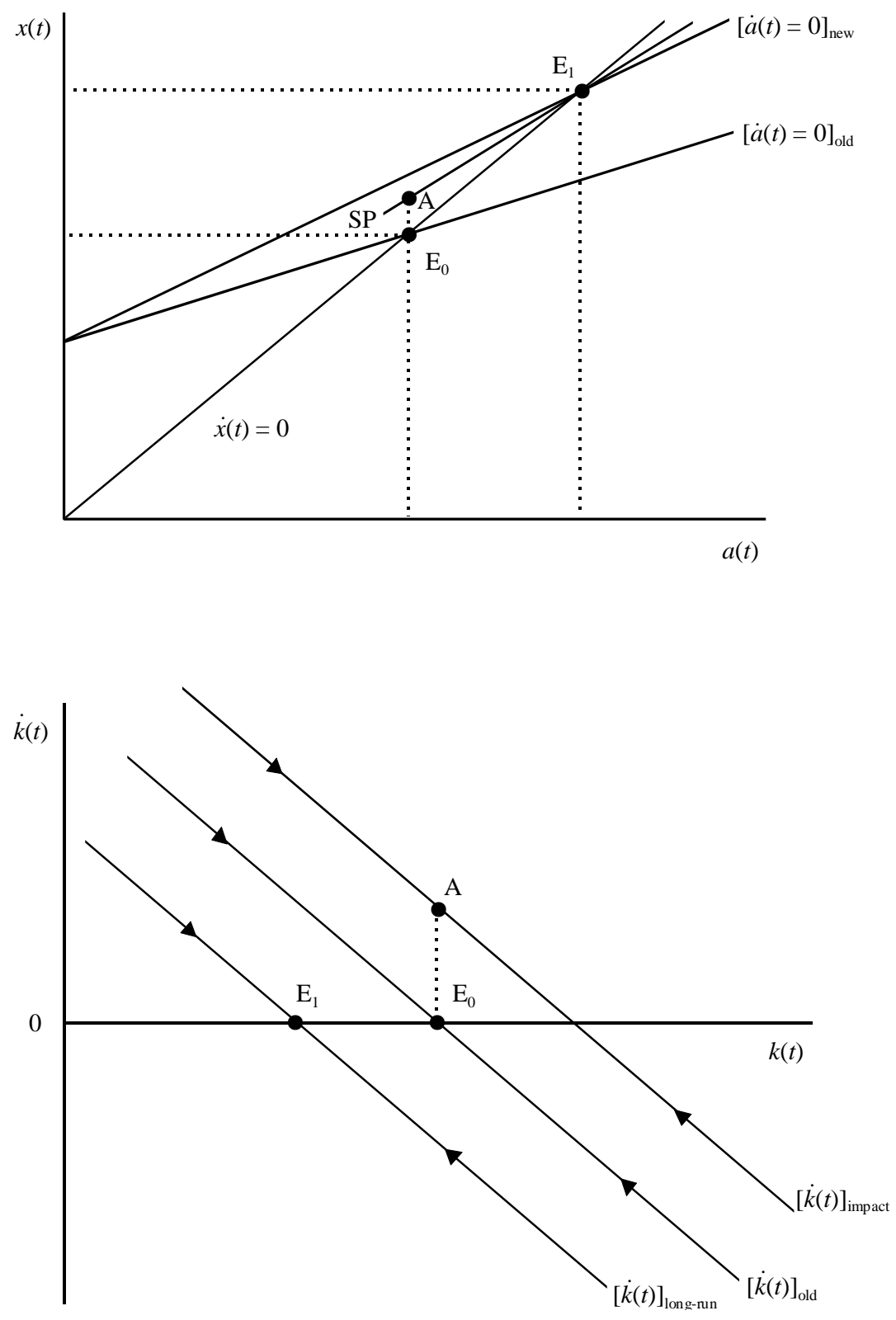

Figure 3: Population Growth Effect 


\subsection{Pension shocks}

In this sub-section we study the macroeconomic effects of shocks in the pension system. We hold the demographic parameters $(\beta$ and $\eta)$ constant and allow for both age-dependent productivity $(\alpha>0)$ and a pre-existing pension system $\left(\bar{z}_{R}>0\right.$ so that $\gamma>0$ in (3.7)). Using (3.7), we find that the $\dot{x}(t)=0$ line can be written as follows:

$$
x(t)=\left(\frac{\rho+\beta}{r^{F}-\rho+\alpha}\right)[\eta \gamma+(\alpha+\eta) a(t)],
$$

where the expression for $\gamma$ is given in (T1.17). The dynamics for full consumption are the same as before, i.e. full consumption rises (falls) for points above (below) the $\dot{x}(t)=0$ line - see Figure 4.

The first shock we consider is a pension reform, consisting of a decrease in the pension payment, $\bar{z}_{R}$. The impact, transitional, and long-run effects of this shock are illustrated in Figure 4. It follows from (T1.17) that $\partial \gamma / \partial \bar{z}_{R}>0$ so that the $\dot{x}(t)=0$ line shifts down, say from $[\dot{x}(t)=0]_{\text {old }}$ to $[\dot{x}(t)=0]_{n e w}{ }^{29}$ At impact, the economy jumps from $\mathrm{E}_{0}$ to point $\mathrm{A}$ on the new saddle path SP. Full consumption falls because per capita human wealth declines. In the bottom panel of Figure 4, the reduction in the consumption of non-traded goods which occurs at impact boosts net investment and shifts the $\dot{k}(t)$ line up, say from $[\dot{k}(t)]_{\text {old }}$ to $[\dot{k}(t)]_{\text {impact }}$. Immediately following the shock, therefore, the per capita stock of capital starts to rise, i.e. $\dot{k}(0)>0$ at point $\mathrm{A}$.

During transition, the economy moves along the saddle path from A to the new steady state at $\mathrm{E}_{1}$. Both full consumption and financial assets increase, but the capital stock declines in the long run. In the bottom panel, the long-run increase in the consumption of nontradeables crowds out net capital accumulation, i.e. the new steady-state equilibrium is at point $\mathrm{E}_{1}$ which lies to the left of $\mathrm{E}_{0}$.

The second shock affecting the pension system consists of an increase in the pension age, $\pi$. It is shown in the Appendix that $\partial \gamma / \partial \pi<0$, i.e. the adjustment mechanism is qualitatively exactly the same as the one illustrated in Figure 4. In addition to items (iv)-(vi) of Proposition 2 , the key results from this sub-section are as stated in the following proposition. ${ }^{30}$

Proposition 4 Consider the core model and assume that the pension payment is decreased $\left(d \bar{z}_{R}<0\right)$ or the retirement age is increased $(d \pi>0)$. The following results can be established: (i) at impact, $x, c^{T}$, and $c^{N}$ fall, $a, k$, and $a^{F}$ are unchanged, and both $\dot{x}$ and $\dot{k}$ increase; (ii) during transition, $x, c^{T}, c^{N}$ and $a^{F}$ rise monotonically, but following its initial increase, $k$

\footnotetext{
${ }^{29}$ Figure 4 is drawn under the assumption that the initial equilibrium occurs in the positive quadrant. If the pension system is very generous, so that $\gamma$ is high, it may well be the case that the initial equilibrium is associated with negative total financial assets.

${ }^{30}$ Using a one-sector model without investment adjustment costs, Nielsen (1994) finds that a decrease in $\bar{z}_{R}$ does not affect the capital stock and employment at all, and that an increase in $\pi$ increases capital and employment equi-proportionally. In the latter case, the capital stock features a once-off jump at impact.
} 

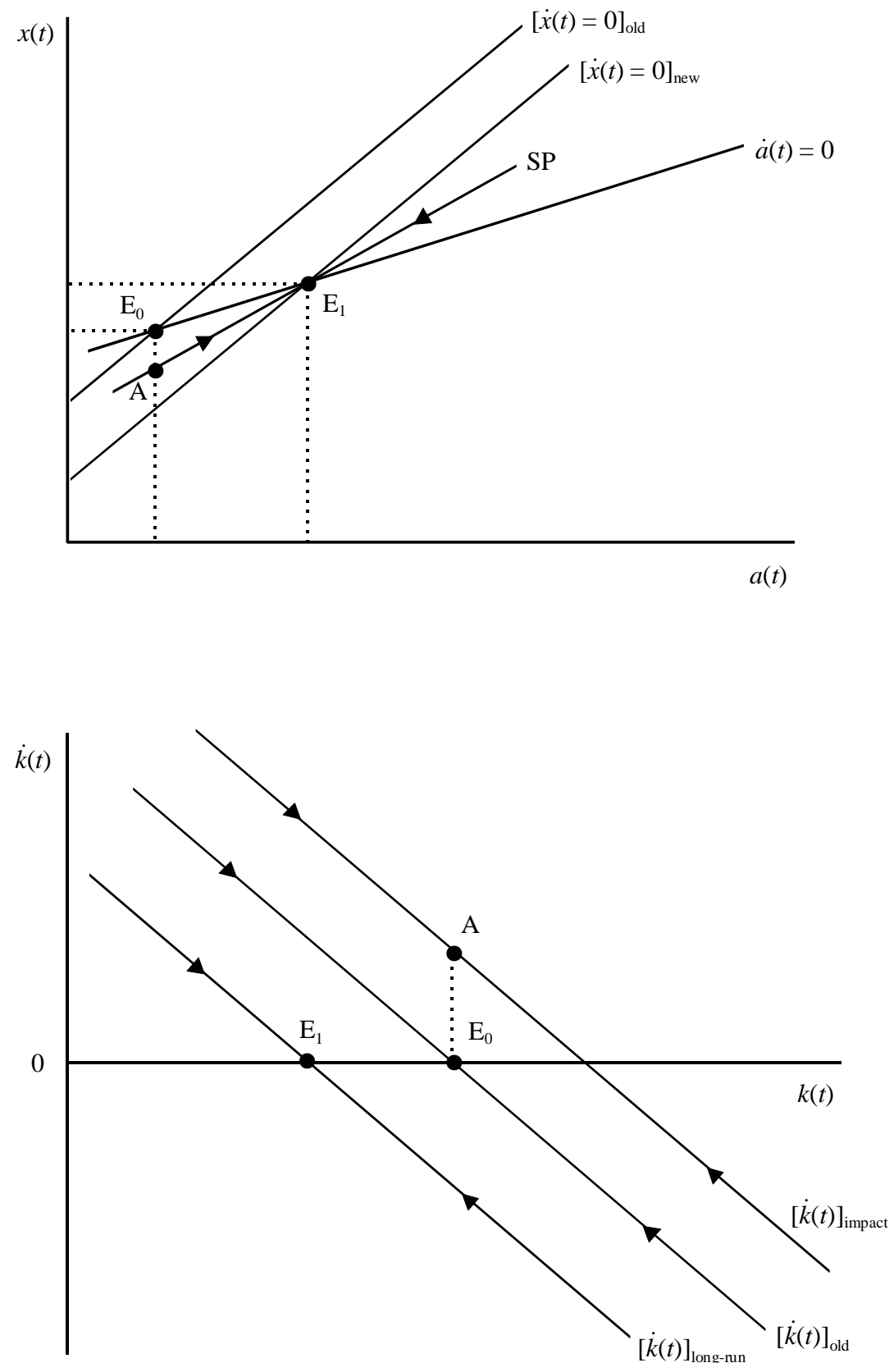

Figure 4: Lower Pension Payment - Higher Pension Age 
starts to decline during the later phases of adjustment; (iii) in the new steady state, $x, c^{T}$, and $c^{N}$ are all increased, but $k$ is decreased.

Proof: see text and Bettendorf and Heijdra (2004).

\section{Welfare effects of pension reform}

In sub-section 3.3 we used the core model to study the macroeconomic effects of pension reform. We found that a decrease in the benefit rate has exactly the same qualitative macroeconomic effects as an increase in the pension age - see Proposition 4. In this section we show that the intergenerational welfare effects associated with the two types of pension reform are nevertheless different. We continue to restrict attention to the core model in the remainder of this section.

\subsection{Welfare measure}

In the core model the welfare measure at time $t$ for a household of vintage $v$ can be written as:

$$
\begin{aligned}
\Lambda(v, t) & \equiv \int_{t}^{\infty}\left[\ln \bar{x}(v, \tau)-\ln \hat{P}_{C}\right] e^{(\rho+\beta)(t-\tau)} d \tau \\
& =\frac{\ln \bar{x}(v, t)-\ln \hat{P}_{C}}{\rho+\beta}+\frac{r^{F}-\rho}{(\rho+\beta)^{2}}
\end{aligned}
$$

where we have used the Euler equation for full consumption to get from the first to the second line. Totally differentiating (4.1) yields:

$$
(\rho+\beta) d \Lambda(v, t)=\tilde{\bar{x}}(v, t)
$$

where $\tilde{\bar{x}}(v, t) \equiv d \bar{x}(v, t) / \hat{\bar{x}}(v, t)$ and we use the approximation $d \ln \bar{x}(v, t) \approx \tilde{\bar{x}}(v, t)$. To evaluate (4.2) we distinguish between existing generations (whose generations index is negative, i.e. $v \leq 0$ ) and future generations (whose index is positive, i.e. $v>0$ ). The time at which the policy shock occurs is normalized to $t=0$.

For existing generations $(v \leq 0)$ we evaluate the effect of pension reform on their remaining lifetime utility, i.e. the relevant welfare measure is $d \Lambda(v, 0)$. It is shown in Bettendorf and Heijdra (2004) that for both types of policy shocks the change in welfare is given by:

$$
(\rho+\beta) d \Lambda(v, t)=\omega_{H}(v) \tilde{\bar{a}}^{H}(v, 0),
$$

where $\omega_{H}(v) \equiv \hat{\bar{a}}^{H}(v, 0) /\left[\hat{\bar{a}}(v, 0)+\hat{\bar{a}}^{H}(v, 0)\right]$ and $\tilde{\bar{a}}^{H}(v, 0) \equiv d \bar{a}^{H}(v, 0) / \hat{\bar{a}}^{H}(v, 0)$. Since asset prices and the interest rate are fixed, the welfare effect is proportional to the proportional change in human wealth. The share of human wealth in total wealth also features in this expression because existing generations have had time to accumulate financial assets (i.e. $\hat{\bar{a}}(v, 0)$ is non-zero for $v<0)$. 
For future generations $(v=t>0)$ we evaluate the effect on lifetime utility of future newborns, i.e. the welfare measure is $d \Lambda(t, t)$. Since newborns enter life without any financial assets, and there is no transitional dynamics in human wealth, their welfare effect can be written as:

$$
(\rho+\beta) d \Lambda(t, t)=\tilde{\bar{a}}^{H}(0,0)
$$

The welfare effects on all (present and future) generations can now be characterized with the aid of (4.3)-(4.4). The critical ingredients needed for this analysis are $\omega_{H}(v)$ and $\tilde{\bar{a}}^{H}(v, 0)$ for $v \in(-\infty, 0]$. In the next two sub-sections we derive expressions for these components for the two types of pension reform.

\subsection{Reduction in the pension payment}

The intergenerational welfare profile associated with a decrease in the pension benefit payment is illustrated in Figure 5. The intuition behind these effects is as follows. For retired households the welfare effect can be written as:

$$
(\rho+\beta) d \Lambda(v, 0)=\Gamma(v) \tilde{\bar{z}}_{R},
$$

where $\Gamma(v)$ is non-negative and increasing in $v$ (for $v \in(-\infty,-\pi)$ ). All retired households loose out as a result of the pension reduction, though less so the older they are. The agedependency follows from the fact that financial asset holdings increase with age so that the share of human wealth in total wealth falls with age. As a result, extremely old generations do not experience a first-order welfare effect of the pension reduction because to them human wealth is negligible (i.e. $\lim _{v \rightarrow-\infty} d \Lambda(v, 0)=0$ ).

For working-age generations the welfare effect can still be written as in (4.5) but $\Gamma(v)$ is decreasing in $v$ for $v \in[-\pi, 0]$. Furthermore, it is easy to show that $\Gamma(-\pi)>0$ and $\Gamma(0)<0$ so that there exists a critical generation for which members the change in the pension payment has no first-order welfare effect (i.e. $\Gamma\left(v^{*}\right)=0$ ). On the one hand members of this generation receive lower pension payments in the future, but on the other hand the pension premiums they have to pay until reaching pension age fall as well (and by the same amount in present-value terms). The age of this critical generation (at time $t=0$ ) is equal to:

$$
-v^{*} \equiv\left(\frac{r^{F}-n_{L}}{r^{F}+\beta}\right) \pi
$$

Working-age generations older (younger) than the critical generation loose out (gain) as a result of the pension reform.

For all future generations the welfare effect can be written as $(\rho+\beta) d \Lambda(t, t)=\Gamma(0) \tilde{\bar{z}}_{R}<$ 0 . With the Aaron condition $\left(r^{F}>n_{L}\right)$ holding, the PAYG system forces these generations to save at an implicit rate of return of $n_{L}$ whereas the market rate of return is $r^{F}$. Hence, as 
far as future generations are concerned, the smaller the pension system is, the better off they are.

The fact that at least some of the generations alive at the time of the shock are better off as a result of it suggests that it may be possible to obtain a majority in parliament in favour of pension reform. Indeed, the proportion of the population which favours pension reform (at time $t=0)$ is equal to:

$$
\frac{L(0)^{\text {pro }}}{L(0)}=1-e^{\eta v^{*}}
$$

where $L(0)^{\text {pro }}$ is the population aged between 0 and $-v^{*}$ and we have used (2.19) and (4.6). The reform proposal commands a majority if $-\eta v^{*}>\ln 2$, or:

$$
\eta\left(\frac{r^{F}-\eta+\beta}{r^{F}+\beta}\right) \pi>\ln 2
$$

Plugging in some illustrative numbers we find that this condition is not very strict. For example, setting $r^{F}=0.06, \beta=0.01, \eta=0.02$ (all per annum), we find that the condition is satisfied provided $\pi>48.5$ years, which is not unreasonable given the implied expected remaining lifetime of the population of $1 / \beta=100$ years. Of course, in a standard twogeneration Diamond (1965) model the pro-reformers (the young) will always command a majority provided there is positive population growth. In contrast, in our model it is quite possible for there to be a majority in favour of reform even if net population growth is negative. Indeed, if $\beta=0.02$ and $\eta=0.015$, the condition (4.8) is satisfied provided $\pi>56.8$ years. By incorporating a more detailed description of demography, our model allows for more population heterogeneity and shows more clearly the different mechanisms affecting the possibility for majoritarian pension reform.

\subsection{Increase in the pension age}

The intergenerational welfare profile associated with an increase in the pension age is illustrated in Figure 6. The key features of this welfare profile are as follows. First, and rather obviously, all retired generations are unaffected by the pension reform, i.e. $d \Lambda(v, 0)=0$ for $v<-\pi$. Second, future generations benefit from the reform since the Aaron condition holds, i.e. $r^{F}>n_{L}$. Intuitively, the increase in $\pi$ decreases the old-age dependency ratio and effectively makes the distorting PAYG system smaller.

The "generational turbulence" associated with the pension reform hits the working-age generations. Worst affected are those generations just about to receive their pensions. They face some additional years during which they are now forced to pay pension premiums whereas they would have received pension payments had the system not been reformed. The younger of the working-age generations benefit from the reform because for them its efficiency-enhancing aspect is relatively more important. Indeed, if $r^{F}>n_{L}$, the critical generation which just 


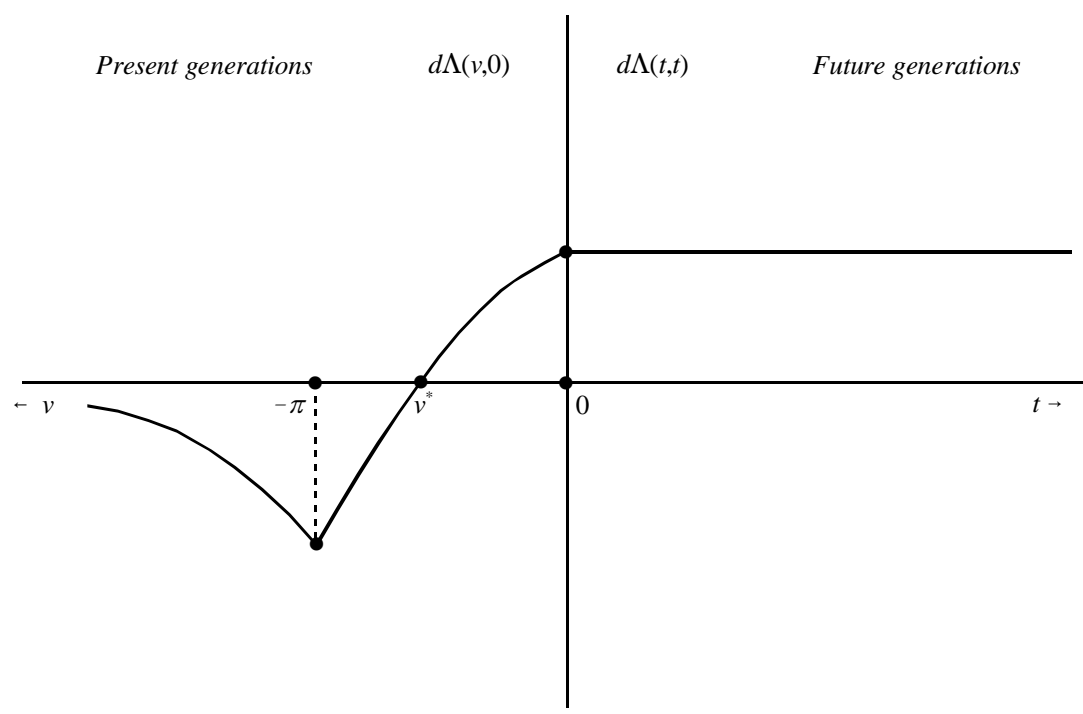

Figure 5: Intergenerational Welfare Effects of a Pension Benefit Reduction

breaks even as a result of the reform has a generations index $v^{\prime}$ :

$$
-v^{\prime} \equiv\left[1+\frac{1}{\left(r^{F}-n_{L}\right) \pi} \ln \left(\frac{\varepsilon}{\varepsilon+\left(r^{F}-n_{L}\right) \pi}\right)\right] \pi,
$$

where $-\pi<v^{\prime}<0$ and where $\varepsilon>1$ is the elasticity of the old-age dependency ratio with respect to the pension age (defined directly below $(2.19)) .{ }^{31}$

Just as for the first pension shock, the condition for the existence of a parliamentary majority in favour of reform is quite reasonable. ${ }^{32}$ For example, holding constant $r^{F}=0.06$, such a majority exists for the parameter settings $\eta=0.02$ and $\beta=0.01$ if $\pi>54.2$ years, whilst for the settings $\eta=0.015$ and $\beta=0.02$ it exists if $\pi>66.5$ years.

\section{Conclusions}

We have studied how population ageing and pension reform affect a small open economy with a non-traded goods sector and with overlapping generations of finite-lived households. Our main findings have been summarized in a number of propositions throughout the text and thus need not be restated here. Among other things, the paper highlights the role played by the non-traded goods sector. By assuming that the investment good is non-tradeable, physical capital is immobile internationally and there are economy-wide adjustment costs of investment which give rise to a well-defined investment policy and thus to a finite convergence

\footnotetext{
${ }^{31}$ In the special "golden-rule" case with $r^{F}=n_{L}$, the change in the dependency ratio has no first-order welfare effect on any generation because the PAYG system is non-distorting.

${ }^{32}$ Although the pension-age generations are indifferent about this type of pension reform, we implicitly count them as opponents. We thus understate the support for reform.
} 


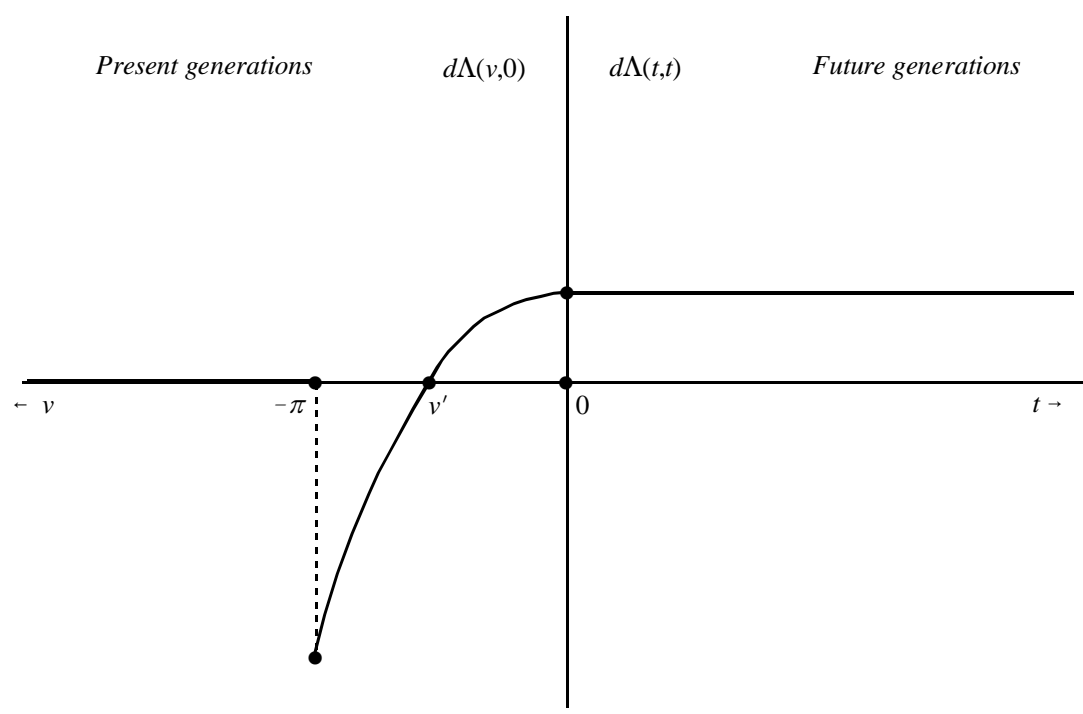

Figure 6: Intergenerational Welfare Effects of an Extension in the Pension Age

speed in the economy. Interestingly, policies which would lead to additional long-run capital formation in a closed economy setting (e.g., a reduction in the pension payment), here lead to crowding out of physical capital even though total assets increase.

The paper can be extended in a number of directions, all of which we plan to pursue in the near future. First, it would probably be useful to endogenize the household labour supply decision. In doing so, the model could be used to study the induced-retirement effect stressed by Feldstein (1974), Kotlikoff (1979), and others. Especially in the context of pension reform this model extension could significantly affect the conclusions of the present paper.

Second, as we have argued in various places in the paper, a number of famous international trade theorems, such as the factor-price equalization theorem, the Stolper-Samuelson theorem, and the Rybczynski theorem, exert a rather dominant effect on the supply side of the model and on the form of the transitional dynamics. It would be useful to move beyond the rather special two-goods-two-factors case used in this paper (and in much of the literature), and to examine the issue of ageing and pension reform in a world in which one or all of these theorems are no longer valid. ${ }^{33}$

\footnotetext{
${ }^{33}$ Two model extensions spring to mind. First, one can examine the specific-factor model of Jones (1971), Neary (1978), Mussa (1974), and Mayer (1974). Second, one could examine limited intersectoral capital mobility, for example due to a concave capital distribution technology in which raw capital is transformed into sector-specific capital services. See, inter alia, Keller (1980) and Gavin (1991).
} 


\section{Appendix}

In this brief appendix we derive some key results used in the paper. More detailed derivations are presented in Bettendorf and Heijdra (2004).

\section{Derivation of the aggregate Euler equation}

Equation (2.24) can be obtained from (2.23) in the following fashion. Since new generations are born without any financial assets $(\bar{a}(t, t)=0)$, it follows from $(2.9)$ that $\bar{x}(t, t)=$ $\Delta(t)^{-1} \bar{a}^{H}(t, t)$ so that the generational turnover term in (2.23) can be simplified to:

$$
\frac{\eta L(t) \bar{x}(t, t)-\beta X(t)}{X(t)}=\frac{\eta L(t) \bar{a}^{H}(t, t)-\beta\left[A(t)+A^{H}(t)\right]}{\Delta(t) X(t)} .
$$

It is not difficult to show that $\eta L(t) \bar{a}^{H}(t, t)$ can be rewritten in terms of aggregate human wealth plus a term involving parameters of the pension system:

$$
\eta L(t) \bar{a}^{H}(t, t)=(\alpha+\eta) A^{H}(t)-\eta \gamma L(t)
$$

where $\gamma$ is defined in (2.25) above. By using (A.2) in (A.1) and noting (2.21) we find that the generational turnover term takes the following form:

$$
\frac{\eta L(t) \bar{x}(t, t)-\beta X(t)}{X(t)}=\alpha+n_{L}-\frac{\eta \gamma L(t)+(\alpha+\eta) A(t)}{\Delta(t) X(t)},
$$

where we have used the fact that $n_{L} \equiv \eta-\beta$ (see (2.15)). Finally, by substituting (A.3) into (2.23) we obtain (2.24).

\section{Transitional dynamics in the core model}

In order to derive the results for section 3.2, we loglinearize equations (3.6)-(3.8) around an initial steady state, noting that $\alpha=\gamma=0$ and defining $\phi \equiv \eta(\rho+\beta)$ :

$$
\begin{aligned}
& \dot{\tilde{k}}(t)=\left(\frac{\hat{y}^{N}}{\hat{k}}\right) \tilde{n}^{N}(t)-\left(\frac{\hat{c}^{N}}{\hat{k}}\right) \tilde{x}(t)-\left(\delta+n_{L}\right) \tilde{k}(t)-d n_{L}, \\
& \dot{\tilde{x}}(t)=\left(r^{F}-\rho\right)\left[\tilde{x}(t)-\frac{1}{\omega_{A T}} \tilde{a}(t)\right]-\frac{\hat{a}}{\hat{x}} d \phi \\
& \dot{\tilde{a}}(t)=\left(r^{F}-n_{L}\right) \tilde{a}(t)-\frac{\hat{x}}{\hat{a}} \omega_{A T} \tilde{x}(t)-\omega_{A T} d n_{L},
\end{aligned}
$$

where $\omega_{A T} \equiv r^{F} \hat{a} /\left(\hat{n}^{T} \hat{y}^{T}\right)>0$ and where a variable with a tilde denotes its rate of change around the initial steady-state, e.g. $\tilde{x}(t) \equiv d x(t) / \hat{x}$. A variable with a tilde and a dot is the change in the time derivative expressed in terms of the initial steady-state, for example, $\dot{\tilde{x}}(t) \equiv d \dot{x}(t) / \hat{x}$. The only exceptions to that convention refer to the financial assets:

$$
\tilde{a}(t) \equiv \frac{r^{F} d a(t)}{\hat{n}^{T} \hat{y}^{T}}, \quad \dot{\tilde{a}}(t) \equiv \frac{r^{F} d \dot{a}(t)}{\hat{n}^{T} \hat{y}^{T}} .
$$


Bettendorf and Heijdra (2004) derive the following reduced-form expression for $\tilde{n}^{N}(t)$ :

$$
\tilde{n}^{N}(t)=-\mu \tilde{k}(t)
$$

where $\mu>0$ follows from the factor-intensity assumption $\left(k^{T}>k^{N}\right)$.

In sub-section 3.2.1 we set $d \eta=d \beta$ so that $d n_{L}=0$ and $d \phi=(\eta+\rho+\beta) d \eta<0$. In subsection 3.2.2, we set $-\eta d \beta=(\rho+\beta) d \eta<0$ so that $d \phi=0$ and $\eta d n_{L}=(\eta+\rho+\beta) d \eta<0$.

\section{Consumption-saving dynamics}

The $(x, a)$-system can be written as:

$$
\left[\begin{array}{c}
\dot{\tilde{x}}(t) \\
\dot{\tilde{a}}(t)
\end{array}\right]=\Pi\left[\begin{array}{c}
\tilde{x}(t) \\
\tilde{a}(t)
\end{array}\right]-\Gamma\left[\begin{array}{c}
d n_{L} \\
d \phi
\end{array}\right],
$$

where $\Pi$ and $\Gamma$ are defined as:

$$
\Pi \equiv\left[\begin{array}{cc}
r^{F}-\rho & -\left(\frac{r^{F}-\rho}{\omega_{A T}}\right) \\
-\frac{\hat{x}}{\hat{a}} \omega_{A T} & r^{F}-n_{L}
\end{array}\right], \quad \Gamma \equiv\left[\begin{array}{cc}
0 & \frac{\hat{a}}{\hat{x}} \\
\omega_{A T} & 0
\end{array}\right] .
$$

The characteristic roots of the Jacobian matrix $\Pi$ are given by $-\lambda_{1} \equiv-\left(\eta+\rho-r^{F}\right)<0$ and $\lambda_{2} \equiv r^{F}+\beta>0$ and we note that $|\Pi|=-\lambda_{1} \lambda_{2}<0$.

The long-run effects are obtained by imposing the steady state in (A.9):

$$
\begin{aligned}
{\left[\begin{array}{c}
\tilde{x}(\infty) \\
\tilde{a}(\infty)
\end{array}\right] } & =\Pi^{-1} \Gamma\left[\begin{array}{c}
d n_{L} \\
d \phi
\end{array}\right] \\
& =\frac{1}{-\left(\eta+\rho-r^{F}\right)\left(r^{F}+\beta\right)}\left[\begin{array}{cc}
r^{F}-\rho & \left(r^{F}-n_{L}\right) \frac{\hat{a}}{\hat{x}} \\
\left(r^{F}-\rho\right) \omega_{A T} & \omega_{A T}
\end{array}\right]\left[\begin{array}{c}
d n_{L} \\
d \phi
\end{array}\right] .
\end{aligned}
$$

Since $r^{F}>\rho$, a reduction in the population growth rate, increases both $x$ and $a$ in the long run. Similarly, a reduction in the generational turnover parameter $\phi$, increases $x$ and $a$ since $r^{F}>n_{L}$.

The impact effects of the shocks are derived with the aid of Laplace transforms. ${ }^{34}$ The impact jump in full consumption is determined by the following condition:

$$
\operatorname{adj}\left[\lambda_{2} I-\Pi\right]\left[\begin{array}{c}
\tilde{x}(0)-\frac{\hat{a}}{\hat{x}} \frac{d \phi}{\lambda_{2}} \\
-\omega_{A T} \frac{d n_{L}}{\lambda_{2}}
\end{array}\right]=\left[\begin{array}{l}
0 \\
0
\end{array}\right],
$$

where $\lambda_{2} \equiv r^{F}+\beta$ is the unstable characteristic root and $\operatorname{adj}\left[\lambda_{2} I-\Pi\right]$ is given by:

$$
\operatorname{adj}\left[\lambda_{2} I-\Pi\right] \equiv\left[\begin{array}{cc}
\eta & -\left(\frac{r^{F}-\rho}{\omega_{A T}}\right) \\
-\frac{\hat{x}}{\hat{a}} \omega_{A T} & \rho+\beta
\end{array}\right] .
$$

\footnotetext{
${ }^{34}$ This method was introduced into economics by Judd (1982). A detailed textbook description of how the method works is found in Heijdra and van der Ploeg (2002, pp. 678-694).
} 
Either row of (A.12) can be used to compute $\tilde{x}(0)$ :

$$
\tilde{x}(0)=\frac{r^{F}-\rho}{\eta\left(r^{F}+\beta\right)}\left[\frac{d \phi}{\rho+\beta}-d n_{L}\right],
$$

where we have used the fact that $\hat{a} / \hat{x}=\left(r^{F}-\rho\right) /(\eta(\rho+\beta))$ to simplify the expression. A reduction in $\phi$ (or an increase in $n_{L}$ ) leads to a decrease in full consumption at impact.

The transitional dynamics is dictated by the stable root of the $(x, a)$-system $\left(-\lambda_{1}\right)$ :

$$
\left[\begin{array}{c}
\tilde{x}(t) \\
\tilde{a}(t)
\end{array}\right]=e^{-\left(\eta+\rho-r^{F}\right) t}\left[\begin{array}{c}
\tilde{x}(0) \\
0
\end{array}\right]+\left[1-e^{-\left(\eta+\rho-r^{F}\right) t}\right]\left[\begin{array}{c}
\tilde{x}(\infty) \\
\tilde{a}(\infty)
\end{array}\right] .
$$

\section{Capital dynamics}

By using (A.4) and (A.8) the differential equation for $k$ can be written as:

$$
\dot{\tilde{k}}(t)=-\lambda_{3} \tilde{k}(t)-\left(\frac{\hat{c}^{N}}{\hat{k}}\right) \tilde{x}(t)-d n_{L},
$$

where $-\lambda_{3} \equiv-\left(\mu \hat{y}^{N} \hat{n}^{N} / \hat{k}+\delta+n_{L}\right)<0$ is the stable root of the investment system. Equation (A.16) is a stable differential equation with a time-varying forcing term $(\tilde{x}(t))$ which is solved subject to the initial condition $\tilde{k}(0)=0$. The long-run effect is obtained by imposing the steady state in (A.16):

$$
\tilde{k}(\infty)=-\frac{1}{\lambda_{3}}\left[\left(\frac{\hat{c}^{N}}{\hat{k}}\right) \tilde{x}(\infty)+d n_{L}\right]
$$

where $\tilde{x}(\infty)$ is given in (A.11) above.

Using the Laplace transform technique and noting (A.15) we find the following solution for the transition path:

$$
\tilde{k}(t)=\left[1-e^{-\lambda_{3} t}\right] \tilde{k}(\infty)+\left(\frac{\hat{c}^{N}}{\hat{k}}\right)[\tilde{x}(\infty)-\tilde{x}(0)] \mathrm{T}\left(\lambda_{1}, \lambda_{3}, t\right),
$$

where $\mathrm{T}\left(\lambda_{1}, \lambda_{3}, t\right)$ is a bell-shaped non-negative, and single-peaked temporary transition term about which the following useful properties can be established.

Lemma A.1 Let $\mathrm{T}\left(\alpha_{1}, \alpha_{2}, t\right)$ be a single transition function of the form:

$$
\mathrm{T}\left(\alpha_{1}, \alpha_{2}, t\right) \equiv \begin{cases}\frac{e^{-\alpha_{2} t}-e^{-\alpha_{1} t}}{\alpha_{1}-\alpha_{2}} & \text { for } \alpha_{1} \neq \alpha_{2} \\ t e^{-\alpha_{1} t} & \text { for } \alpha_{1}=\alpha_{2},\end{cases}
$$

with $\alpha_{1}>0$ and $\alpha_{2}>0$. Then $\mathrm{T}\left(\alpha_{1}, \alpha_{2}, t\right)$ has the following properties: (i) (positive) $\mathrm{T}\left(\alpha_{1}, \alpha_{2}, t\right)>0 t \in(0, \infty)$, (ii) $\mathrm{T}\left(\alpha_{1}, \alpha_{2}, t\right)=0$ for $t=0$ and in the limit as $t \rightarrow \infty$, (iii) (single-peaked) $d \mathrm{~T}\left(\alpha_{1}, \alpha_{2}, t\right) / d t>0$ for $t \in(0, \hat{t}), d \mathrm{~T}\left(\alpha_{1}, \alpha_{2}, t\right) / d t<0$ for $t \in(\hat{t}, \infty)$, $d \mathrm{~T}\left(\alpha_{1}, \alpha_{2}, t\right) / d t=0$ for $t=\hat{t}$ and in the limit as $t \rightarrow \infty$, and $d \mathrm{~T}\left(\alpha_{1}, \alpha_{2}, 0\right) / d t=1$, (iv) $\hat{t} \equiv \ln \left(\alpha_{1} / \alpha_{2}\right) /\left(\alpha_{1}-\alpha_{2}\right)$ if $\alpha_{1} \neq \alpha_{2}$ and $\hat{t} \equiv 1 / \alpha_{1}$ if $\alpha_{1}=\alpha_{2}$; (v) (point of inflexion) $d^{2} \mathrm{~T}\left(\alpha_{1}, \alpha_{2}, t\right) / d t^{2}=0$ for $t=2 \hat{t}$

Proof: obvious. 


\section{Dynamics and pension shocks}

In order to derive the results for section 3.3, we hold $\eta$ and $\beta$ constant (so that $d n_{L}=d \phi=0$ ), and note that $\alpha \geq 0$ and $\bar{z}_{R}>0$. Apart from the fact that $d n_{L}=0$, equations (A.4) and (A.6) are unaffected but (A.5) is changed to:

$$
\dot{\tilde{x}}(t)=\left(r^{F}-\rho+\alpha\right)\left[\tilde{x}(t)-\frac{\zeta}{\omega_{A T}} \tilde{a}(t)-(1-\zeta) \tilde{\gamma}\right],
$$

where $\phi \equiv(\alpha+\eta)(\rho+\beta)$ and $\zeta$ is defined as:

$$
0<\zeta \equiv \frac{\phi \hat{a}}{\phi \hat{a}+(\rho+\beta) \eta \gamma}<1 .
$$

Following the same steps as before we find that the characteristic roots of the consumptionsaving system are $-\lambda_{1} \equiv-\left(\eta+\rho-r^{F}\right)<0$ and $\lambda_{2} \equiv r^{F}+\alpha+\beta>0$, and that the transition path following a pension shock is given by (A.15) with:

$$
\begin{aligned}
\tilde{x}(0) & =\frac{(1-\zeta)\left(r^{F}-\rho+\alpha\right)}{r^{F}+\alpha+\beta} \tilde{\gamma} \\
{\left[\begin{array}{c}
\tilde{x}(\infty) \\
\tilde{a}(\infty)
\end{array}\right] } & =\frac{(1-\zeta)\left(r^{F}-\rho+\alpha\right)}{-\left(\eta+\rho-r^{F}\right)\left(r^{F}+\alpha+\beta\right)}\left[\begin{array}{c}
r^{F}-n_{L} \\
\frac{\hat{x}}{\hat{a}} \omega_{A T}
\end{array}\right] \tilde{\gamma} .
\end{aligned}
$$

The transition path for the per capita capital stock still takes the form as given in (A.18).

\section{Comparative static effects for $\gamma$}

The pension-related term $\gamma$ is defined in (2.25) above. We write it as follows:

$$
\gamma \equiv\left(\frac{1}{1-e^{-\eta \pi}}\right)\left(\frac{\bar{z}_{R}}{r^{F}+\beta}\right)\left(r^{F}+\alpha+\beta\right)\left(\frac{e^{-\eta \pi}-e^{-\left(r^{F}+\beta\right) \pi}}{r^{F}+\beta-\eta}\right)>0,
$$

where we have used the fact that $n_{L} \equiv \eta-\beta$. The partial derivative with respect to $\bar{z}_{R}$ is straightforward: $\partial \gamma / \partial \bar{z}_{R}=\gamma / \bar{z}_{R}>0$. The partial derivatives for $\eta, \beta$, and $\pi$ are more complicated.

\section{Birth rate}

For the birth rate we find:

$$
\frac{\partial \eta \gamma}{\partial \eta}=\eta \gamma \pi\left[\Psi[\eta \pi]-\Psi\left[\left(\eta-r^{F}-\beta\right) \pi\right]\right]<0,
$$

where $\Psi(x)$ is defined as follows:

$$
\Psi(x) \equiv \frac{1}{x}-\frac{1}{e^{x}-1} .
$$

The following Lemma establishes some important properties of $\Psi(x)$. 
Lemma A.2 Let $\Psi(x) \equiv \frac{1}{x}-\frac{1}{e^{x}-1}$. Then: (i) $\Psi(x)>0$; (ii) $\Psi^{\prime}(x)<0, \forall x$.

Proof: See Bettendorf and Heijdra (2004).

Lemma A.2 establishes that $\Psi(x)$ is a decreasing function. Since $\eta \pi<\left(\eta-r^{F}-\beta\right) \pi$, the inequality in (A.24) follows readily.

\section{Death rate}

After some steps, we find that the derivative of $\gamma$ with respect to the mortality rate $\beta$ is:

$$
\frac{\partial \gamma}{\partial \beta}=-\gamma\left[\pi \Psi\left[\left(r^{F}+\beta-\eta\right) \pi\right]+\frac{\alpha}{\left(r^{F}+\beta+\alpha\right)\left(r^{F}+\beta\right)}\right]<0
$$

where the sign follows from the fact that $\Psi(x)>0, \forall x$ (see Lemma A.2(i)). Hence, $\gamma$ is a downward sloping function of the death rate, $\beta$.

\section{Pension age}

Finally, the derivative with respect to the pension age can be written as follows.

$$
\frac{\partial \gamma}{\partial \pi} \equiv\left(\frac{\bar{z}_{R}}{r^{F}+\beta-\eta}\right)\left(\frac{r^{F}+\alpha+\beta}{r^{F}+\beta}\right) \frac{\partial}{\partial \pi}\left(\frac{1-e^{-\left(r^{F}+\beta-\eta\right) \pi}}{e^{\eta \pi}-1}\right),
$$

with:

$$
\frac{\partial(\cdot)}{\partial \pi}=\frac{e^{-\left(r^{F}+\beta-\eta\right) \pi}\left(r^{F}+\beta\right) \eta \pi}{\left(e^{\eta \pi}-1\right)^{2}}\left[\Xi[\eta \pi]-\Xi\left[\left(r^{F}+\beta\right) \pi\right]\right] .
$$

The $\Xi(x)$ function is defined as follows:

$$
\Xi(x) \equiv \frac{e^{x}-1}{x}>0, \quad \text { for } x \geq 0 .
$$

It is straightforward to verify that $\Xi^{\prime}(x)>0$ for $x \geq 0$. It follows from (A.28) that:

$$
\begin{array}{rlrl}
\frac{\partial(\cdot)}{\partial \pi} & < & & > \\
& >0 & r^{F} & =\eta-\beta\left[\equiv n_{L}\right] . \\
& & <
\end{array}
$$

Hence, it follows from (A.27) that:

$$
\frac{\partial \gamma}{\partial \pi} \equiv\left(\frac{\bar{z}_{R}}{r^{F}+\beta-\eta}\right)\left(\frac{r^{F}+\alpha+\beta}{r^{F}+\beta}\right) \frac{\partial(\cdot)}{\partial \pi}<0,
$$

since $r^{F}+\beta-\eta$ has the opposite sign of $\partial(\cdot) / \partial \pi$. Hence, $\gamma$ decreases with the pension age $\pi$. 


\section{References}

Armington, P. S. (1969). A theory of demand for products distinguished by place of production. IMF Staff Papers, 16:159-178.

Auerbach, A., Kotlikoff, L., Hagemann, R., and Nicoletti, G. (1989). The economic dynamics of an aging population: The case of four OECD countries. OECD Economic Studies, 12:97-130.

Auerbach, A. J., Cai, J., and Kotlikoff, L. J. (1991). U.S. demographics and saving: Predictions of three savings models. Carnegie-Rochester Conference Series on Public Policy, $34: 135-156$.

Auerbach, A. J. and Kotlikoff, L. J. (1987). Dynamic Fiscal Policy. Cambridge University Press, Cambridge.

Bettendorf, L. J. H. and Heijdra, B. J. (2004). Population ageing and pension reform in a small open economy with non-traded goods: Mathematical Appendix. Unpublished Paper, University of Groningen. Download from: http://www. eco.rug.nl/medewerk/heijdra/leon4app.pdf.

Blanchard, O.-J. (1985). Debts, deficits, and finite horizons. Journal of Political Economy, 93:223-247.

Bovenberg, A. L. (1993). Investment promoting policies in open economies: The importance of intergenerational and international distributional effects. Journal of Public Economics, $51: 3-54$.

Brock, P. L. and Turnovsky, S. J. (1994). The dependent economy model with both traded and nontraded capital goods. Review of International Economics, 2:306-201.

Broer, D. P. (2001). Growth and welfare distribution in an ageing society: An applied general equilibrium analysis for the Netherlands. De Economist, 149:81-114.

Buiter, W. H. (1988). Death, birth, productivity growth and debt neutrality. Economic Journal, 98:279-293.

Cutler, D. M., Poterba, J. M., Sheiner, L. M., and Summers, L. H. (1990). An aging society: Opportunity or challenge? Brookings Papers on Economic Activity, 1:1-73.

Diamond, P. A. (1965). National debt in a neoclassical growth model. American Economic Review, 55:1126-1150.

Feldstein, M. S. (1974). Social security, induced retirement, and aggregate capital accumulation. Journal of Political Economy, 82:905-926. 
Gavin, M. (1991). Tariffs and the current account: On the macroeconomics of commercial policy. Journal of Economic Dynamics and Control, 15:27-52.

Gertler, M. (1999). Government debt and social security in a life-cycle model. CarnegieRochester Series on Public Policy, 50:61-117.

Giovannini, A. (1988). The real exchange rate, the capital stock, and fiscal policy. European Economic Review, 32:1747-1767.

Heijdra, B. J. and van der Ploeg, F. (2002). Foundations of Modern Macroeconomics. Oxford University Press, Oxford.

Hsieh, Y.-N., Chang, W.-Y., and Lai, C.-C. (1998). Endogenizing labor-leisure choice: Investment and the relative price of non-traded goods. Economic Letters, 60:105-111.

Hubbard, R. G. and Judd, K. L. (1987). Social security and individual welfare: Precautionary saving, borrowing constraints, and the payroll tax. American Economic Review, 77:630646.

Jones, R. W. (1971). A three-factor model in theory, trade, and history. In Bhagwati, J. N., Jones, R. W., Mundell, R., and Vanek, J., editors, Trade, Balance of Payments, and Growth. North-Holland, Amsterdam.

Judd, K. L. (1982). An alternative to steady-state comparisons in perfect foresight models. Economics Letters, 10:55-59.

Keller, W. J. (1980). Tax Incidence: A General Equilibrium Approach. North-Holland, Amsterdam.

Kotlikoff, L. J. (1979). Social security and equilibrium capital intensity. Quarterly Journal of Economics, 93:233-253.

Lee, R. (2003). The demographic transition: Three centuries of fundamental change. Journal of Economic Perspectives, 17:167-190.

Mayer, W. (1974). Short-run and long-run equilibrium for a small open economy. Journal of Political Economy, 82:955-968.

Mussa, M. (1974). Tariffs and the distribution of income: The importance of factor specificity, substitutability, and intensity in the short and long-run. Journal of Political Economy, 82:1191-1204.

Neary, J. P. (1978). Short-run capital specificity and the pure theory of international trade. Economic Journal, 88:488-510. 
Nielsen, S. B. (1994). Social security and foreign indebtedness in a small open economy. Open Economies Review, 5:47-63.

Turnovsky, S. J. (1997). International Macroeconomic Dynamics. MIT Press, Cambridge, MA.

United Nations (2003). World Population Prospects: The 2002 Revision Population Database. Link: http://www.un.org/esa/population/unpop.htm.

van Wincoop, E. (1993). Structural adjustment and the construction sector. European Economic Review, 37:177-201.

Weil, P. (1989). Overlapping families of infinite-lived agents. Journal of Public Economics, 38:183-198.

Woodland, A. D. (1982). International Trade and Resource Allocation. North-Holland, Amsterdam.

Yaari, M. E. (1965). Uncertain lifetime, life insurance, and the theory of the consumer. Review of Economic Studies, 32:137-150. 